\title{
The Downs-Thomson paradox with imperfect mode substitutes and alternative transit administration regimes
}

\author{
Fangni Zhang ${ }^{\mathrm{a}, 1}$, Robin Lindsey ${ }^{\mathrm{b}}$, Hai Yang ${ }^{\mathrm{a}}$ \\ ${ }^{a}$ Department of Civil and Environmental Engineering, The Hong Kong University of Science \\ and Technology, Clear Water Bay, Kowloon, Hong Kong, China \\ ${ }^{b}$ Sauder School of Business, University of British Columbia, 2053 Main Mall, Vancouver, \\ British Columbia V6T 1Z2, Canada
}

\begin{abstract}
The Downs-Thomson paradox (D-T paradox) occurs when expansion of a congested and untolled highway undermines scale economies of a competing transit service, leaving users of both modes worse off. The standard analysis of the D-T paradox is based on several stringent assumptions: fixed total travel demand, perfect substitutability between automobile and transit trips, and no transit crowding. This paper re-examines the paradox when these assumptions are relaxed while retaining the usual assumption that there is no congestion interaction between the modes. It also broadens consideration to alternative transit administration regimes. In the standard treatment the transit operator is obliged to cover its costs. In this paper we also study two other regimes: transit profit maximization, and system-wide welfare maximization with no financing constraint. We examine how the transit system operator responds to highway capacity expansion in each regime, and how this affects welfare for drivers and transit users. We show that in all regimes the full price of transit declines only if the full price of driving falls as well. Thus, drivers are more likely to benefit from highway expansion than transit riders. The D-T paradox cannot occur in the profit maximization or unconstrained welfare maximization regimes. In the traditional self-financing regime transit service deteriorates, but the D-T paradox is not inevitable. Numerical analysis suggests that it can occur only when automobile and transit trips are nearly perfect substitutes.
\end{abstract}

Key words: Highway expansion; Responsive transit service; Imperfect substitutability; Transit crowding; Downs-Thomson paradox.

\section{Introduction}

Traffic congestion is a severe and growing problem in many cities around the world. In the past, the usual response was to build new roads or expand existing ones. By the late twentieth

\footnotetext{
${ }^{1}$ Corresponding author. Tel.: +85223587175 .

E-mail addresses: fzhangad@connect.ust.hk (F.Zhang), robin.lindsey@sauder.ubc.ca (R. Lindsey), cehyang@ust.hk (H. Yang).
} 
century, however, adding road capacity had become controversial (see Cervero, 2003 for a review) and it has now largely fallen out of favor. Long lead times, high construction costs and usage of scarce land space are one reason. Adverse environmental effects and disturbance of neighborhoods are another.

A third reason is evidence that expanding road capacity encourages more driving so that traffic congestion is not reduced as much as expected (e.g., Goodwin, 1996; Hansen and Huang, 1997). Indeed, Duranton and Turner (2011) found in the case of US interstate highways that distance driven increases in proportion to lane kilometers of capacity. This implies that adding road capacity does not relieve congestion at all. Downs (1962) remarked on this possibility more than fifty years ago, and referred to it as "Downs's Law of Peak-Hour Traffic Congestion". He attributed it to the combined effects of route shifting, retiming of trips toward the peak, and mode shifting from public transport to driving.

Downs further noted that highway expansion could lead not only to a decline in transit ridership, but also a reduction in transit service and/or higher fares. Such a response is possible if the transit operator is obliged to cover its costs, and transit service has scale economies. If so, transit riders end up worse off. Moreover, if enough individuals choose between driving and taking transit on the basis of their full prices, then in the new equilibrium drivers are worse off in aggregate too. Downs's (1962) hypothesis was independently formulated by Thomson (1977) who noted the tendency in many cities for driving and transit to become equally attractive (or unattractive). Mogridge (1987) and Holden (1989) provided further empirical evidence for the hypothesis in areas where public transport is heavily used.

The possibility that highway expansion can make travel conditions worse is striking. Mogridge (1987) dubbed it the "Downs-Thomson paradox" (henceforth D-T paradox). A substantial literature on the paradox has developed; see Arnott and Small (1994) and Zhang et al. (2014) for reviews. ${ }^{2}$ Analytical studies include Mogridge (1997), Williams (1998), Arnott and Yan (2000), Bell and Wichiensin (2012), and Basso and Jara-Díaz (2012). Experiments on the paradox have been conducted by Denant-Boèmont and Hammiche (2009) and Dechenaux et al. (2014). Anderson (2014) and Adler and van Ommeren (2015) have recently shown how transit strikes can severely impact driving speeds, especially during peak periods, thereby demonstrating the potentially strong interaction effects between auto and transit usage. The importance of transit service scale economies is also well-established. It is inherent in Mohring's (1972) classical model, and has been quantified in applied studies too (e.g., Parry and Small, 2009).

The D-T paradox is readily understood, compelling, and sobering as far as the prospects for

\footnotetext{
${ }^{2}$ A similar paradox can occur in computer networks and queuing systems. See Guo et al. (2014) and references cited therein.
} 
alleviating traffic congestion. However, the standard treatment of the paradox as presented by Mogridge (1997) rests on several assumptions. The first is that, as in Mohring's (1972) analysis, the transit operator aims to maximize welfare but faces a budget constraint. If ridership falls, the operator is forced to cut costs and/or raise fares in order to continue meeting the constraint. The cost of transit therefore rises, and ridership drops further in a vicious circle. In practice, transit service may be run with other goals or under different constraints. One possibility is that the transit operator is a profit maximizer. Zhang et al. (2014) have recently proved that in this case the D-T paradox cannot occur. In response to an increase in highway capacity, the operator chooses to limit the loss of patronage by increasing frequency and/or reducing the fare. By contrast, Zhang et al. (2014) proved that the paradox is inevitable in the traditional case of a welfare-maximizing operator subject to a binding self-financing constraint.

Zhang et al. (2014) is notable for showing that a change in the transit operator's objective function can circumvent the D-T paradox. However, their model retains Mogridge's (1997) other assumptions: driving and transit are perfect substitutes, total travel demand is fixed, and transit (unlike driving) is free of congestion. Each of these assumptions can be challenged.

Perfect substitutability: In Mogridge's (1997) analysis, an equilibrium modal split is reached when the full price or generalized cost of travel is the same for driving and taking transit. This assumes that there exists a sufficiently large group of travelers who view the two modes as perfect substitutes in the sense of being indifferent between them. Perfect substitutability implies that the cross-price elasticity of demand between driving and transit is infinite. Yet empirical studies have found that the cross-price elasticity is rather small. Hensher (1998) reported cross-elasticities ranging from 0.08 to 0.7. Dargay and Hanly (1999) reported crosselasticities of 0.05 in the short run, and 0.3 or 0.4 in the long run. Litman (2015) surveys the literature and compiles a set of recommended cross-elasticity values (see his Table 15). For transit ridership with respect to auto operating costs, the range of cross-elasticities is 0.05 to 0.15 in the short term, and 0.2 to 0.4 in the long term. For auto travel with respect to transit costs, the cross-elasticities are even smaller: 0.03 to 0.1 in the short term, and 0.15 to 0.3 in the long term.

Thus, the empirical evidence indicates that auto and transit are highly imperfect substitutes. ${ }^{3}$ It therefore does not make sense to determine the equilibrium modal split between them using an equal-price condition. This point was recognized by some early writers on the D-T paradox including Thomson (1977) himself, and Bly et al. (1987). Mogridge (1997) acknowledged that many travelers are "inframarginal" in the sense of strictly preferring one mode to the other.

\footnotetext{
${ }^{3}$ In a recent study of public transit investment and traffic congestion Beaudoin et al. (2015) estimate an average elasticity of auto travel with respect to transit capacity of -0.08 for 96 urban areas in the U.S. The elasticity varies from -0.02 for small, scarcely populated areas with less-developed transit service, to -0.4 for the largest, most densely populated areas with extensive transit service. Their results suggest that the cross-price elasticities of demand between the two modes vary substantially as well, but are all quite small.
} 
Arnott and Yan (2000) also remarked on the unrealistic nature of perfect substitutability. They extend their model to take it into account, but do not take their analysis far.

Fixed total demand: Particularly at peak times, urban travel demand is generally inelastic in the sense that price elasticities are less than one in magnitude. Nevertheless, the elasticities can be appreciable. According to Litman (2015), peak-period fare elasticities for transit range from -0.15 to -0.3 in the short run, and -0.4 to -0.6 in the long run. Elasticities with respect to the full price of taking transit are higher. Part of the response to fare changes is due to shifts between transit and driving, but the low cross-price elasticity estimates noted above indicate that other behavioral changes must be at play as well such as shifts to or from walking and cycling, and changes in the total number of trips made. Automobile travel demand elasticities are also appreciable (see Litman, 2012) even in areas where transit mode shares are very low. All this indicates that the number of trips made by auto and transit together depends on the price of travel. Treating the sum as fixed is inappropriate for studying the D-T paradox — particularly since the intensity of traffic congestion and transit crowding (see below) depend on the number of trips made by each mode.

Transit congestion and crowding: Mohring's (1972) classical model ignores transit congestion, and it is also absent from Mogridge's (1997) graphical treatment. Yet, like traffic congestion, transit crowding is a growing problem in many cities (OECD, 2014). It can be manifest in various ways including: congestion while accessing stations on walkways and escalators, inability to board transit vehicles that are full, congestion while entering and exiting transit vehicles and while riding on them, prolonged in-vehicle travel times, etc.. Crowding attenuates the attractiveness of transit as an alternative to driving. Moreover, regardless of a transit operator's goals crowding is an important consideration when making fare and capacity decisions as has been demonstrated in recent work; see, for example, de Palma et al. (2015a, b).

In this paper we extend the conventional treatment of the D-T paradox to include imperfect demand substitutability, elastic total travel demand, and transit congestion. We allow for transit congestion in the form of crowding by specifying the cost of taking transit as an increasing function of ridership, and a decreasing function of service frequency. However, we assume that automobile traffic and transit vehicle movements do not interact so that there are no crosscongestion effects between modes. This assumption is realistic for subways, rail, and Bus Rapid Transit systems with a dedicated right-of-way, but not for conventional bus service that shares the road with cars. ${ }^{4}$

In addition to these extensions, we contribute to the literature on the D-T paradox by considering three transit administration regimes: (1) the standard one of social welfare-

\footnotetext{
${ }^{4}$ Interactions between automobiles and buses is considered in Basso et al. (2015) and Beaudoin et al. (2015).
} 
maximization subject to a self-financing constraint, (2) profit-maximization, and (3) unconstrained social welfare-maximization. Zhang et al. (2014) considered the first two regimes, but not the third. We derive some basic properties of each regime, and investigate under what conditions, if any, the D-T paradox can occur in each one.

In independent research Basso et al. (2015) have recently re-examined the D-T paradox from a perspective similar to ours. They, too, allow for elastic total trip demand, imperfect substitutability between driving and transit, and congestion on public transit. Their model also allows for mixed traffic and cross congestion between public transport and car travel. However, their model and analysis differ from ours in several respects. First, congestion takes the form of delays at bus stops rather than crowding aboard vehicles. Second, they limit attention to social-welfare maximizing transit operation while allowing for a parametrically specified percentage subsidy to relax the budget constraint. Third, and most significantly, they use a logit model to describe the modal split between driving and taking transit. This precludes an analytical treatment. They solve their model numerically for the specific case of bus travel in London.

Before studying the D-T paradox it is necessary to clarify what it means. In the standard model the paradox occurs if the price of travel rises. This simple definition is sufficient because the aggregate number of trips is fixed, and the prices of driving and transit are the same in equilibrium. In our more general setting, total demand is elastic and the benefits of travel must therefore be weighed as well as the costs. Moreover, with imperfect substitutability between modes the equilibrium prices of auto and transit trips generally differ. In response to a change in highway capacity, it is possible for the price of one mode to rise while the other falls.

We address these two complications as follows. First, we use a representative consumer model so that we can treat a single full price of each mode and avoid dealing with differences between individuals in such characteristics as values of travel time. Second, we use social surplus as a metric for welfare. Welfare is the sum of the consumers' surplus of the representative consumer (who uses both modes), and the profits of the transit operator. The highway is assumed to be untolled so that toll revenues are not a factor. Third, we formulate two versions of the D-T paradox. The weak version of the paradox occurs if highway capacity expansion reduces welfare. The strong version of the paradox occurs if the full prices of both modes rise, and transit profits either fall or stay the same. Under these conditions, the weak version necessarily occurs as well. In the self-financing regime, transit profits are zero so the strong version of the paradox occurs if the prices of both modes rise. Throughout the analysis we disregard the costs of highway expansion. If these costs were included, the weak version of the paradox based on welfare would, of course, be more likely to occur.

The balance of the paper is organized as follows. Section 2 describes the model. Section 3 takes 
a preliminary step at examining the D-T paradox by assessing the effects of a marginal highway capacity expansion while treating the transit operator's response parametrically. Section 4 derives the transit operator's responses in service frequency and fare in each of the three transit administration regimes. Section 5 explores a linear version of the model. Section 6 presents a numerical example, and Section 7 concludes.

\section{Model setup}

Consider a travel corridor linking a residential area and a central business district. The corridor is served by a congested highway and a parallel transit line with a separate right of way. Let $p_{i}, i=a, b$, denote the full price of travelling by mode $i$, where ' $a$ ' denotes the automobile and ' $b$ ' denotes transit (e.g. rail or Bus Rapid Transit with a dedicated right-of-way). For brevity we will henceforth refer to the full price for each mode as the "price". The demand curves for travel by the two modes are $v_{a}=v_{a}\left(p_{a}, p_{b}\right)$ and $v_{b}=v_{b}\left(p_{a}, p_{b}\right)$. This specification allows the two modes to be imperfect substitutes and total travel demand to be elastic. Demand for each mode is a decreasing function of its own price and an increasing function of the other mode's price so that $\frac{\partial v_{a}}{\partial p_{a}}<0, \frac{\partial v_{b}}{\partial p_{b}}<0, \frac{\partial v_{a}}{\partial p_{b}}>0$, and $\frac{\partial v_{b}}{\partial p_{a}}>0$.

Users are assumed to be identical except for their willingness to pay for a trip so that a representative consumer approach can be used. By concavity of the utility function underlying the demand functions, $\frac{\partial v_{a}}{\partial p_{a}} \frac{\partial v_{b}}{\partial p_{b}}-\frac{\partial v_{a}}{\partial p_{b}} \frac{\partial v_{b}}{\partial p_{a}}>0$ (Arnott and Yan, 2000; Kraus, 2012). Prices of the two modes are:

$$
\begin{aligned}
& p_{a}=\tau_{a}+c_{a}\left(v_{a}, \mathrm{~s}\right), \\
& p_{b}=\tau_{b}+c_{b}\left(v_{b}, f\right) .
\end{aligned}
$$

In Eq. (1), $\tau_{a}$ is the constant monetary cost of driving which includes fuel consumption, vehicle maintenance, and parking fees. There is no toll. The second term, $c_{a}\left(v_{a}, \mathrm{~s}\right)$, is the travel time cost of driving which is an increasing function of traffic volume $v_{a}$, and a decreasing function of highway capacity $s$; i.e., $\partial c_{a} / \partial v_{a}>0$ and $\partial c_{a} / \partial s<0$. Function $c_{a}\left(v_{a}, \mathrm{~s}\right)$ also satisfies $\partial^{2} c_{a} / \partial v_{a}^{2} \geq 0, \partial^{2} c_{a} / \partial s^{2}>0$, and $\partial^{2} c_{a} / \partial v_{a} \partial s<0$.

In Eq. (2), $\tau_{b}$ is the transit fare, $v_{b}$ is transit ridership, and $f$ is service frequency which is treated as a continuous variable. Function $c_{b}\left(v_{b}, f\right)$ comprises non-monetary costs of using transit due to waiting time, boarding and alighting time, in-vehicle travel time, and the disutility incurred from crowding on platforms, escalators, stairways, and aboard vehicles. Higher service frequency reduces average waiting time, boarding and alighting time, and crowding 
costs while in transit. Therefore, $c_{b}\left(v_{b}, f\right)$ is assumed to be increasing with $v_{b}$ and decreasing with $f$; i.e., $\partial c_{b} / \partial v_{b}>0, \partial c_{b} / \partial f<0$. Similar to the automobile user cost function, $c_{b}\left(v_{b}, f\right)$ also satisfies $\partial^{2} c_{b} / \partial v_{b}^{2} \geq 0, \partial^{2} c_{b} / \partial f^{2}>0$, and $\partial^{2} c_{b} / \partial v_{b} \partial f<0$. The operator's cost function for frequency, $K(f)$, is assumed to be a strictly increasing and twice differentiable function of $f$.

Transit service is provided by a single operator which chooses service frequency and fare. To focus on the transit operator's responses to highway expansion, highway capacity is treated as exogenous and the cost of highway expansion is excluded from consideration. The equilibrium modal split, $\left(v_{a}, v_{b}\right)$, is unique for given $\left(\tau_{a}, \tau_{b}, s, f\right)$ due to the monotonicity of the functions defined above. Throughout the analysis we consider only interior equilibria with $v_{a}, v_{b}>0$.

\section{Effects of highway expansion for given transit operator's response}

In this section we consider the effect of a marginal increase of highway capacity on modal volumes and prices while treating the transit operator's response parametrically. ${ }^{5}$ An increase in capacity initially reduces the price of driving and induces some travelers to shift from transit to the car. In response, the transit operator adjusts transit service frequency and fare in accordance with its goals. The combined effect of highway expansion and transit response leads to a new equilibrium. The strong version of D-T paradox occurs if transit profits do not rise and prices of both modes increase; i.e., if

$$
\frac{d p_{i}}{d s}>0, i=a, b \text {. }
$$

If the two modes are perfect substitutes, as in the standard model, $p_{a}$ and $p_{b}$ are necessarily equal in equilibrium and the D-T paradox is inevitable in the self-financing regime if transit service has long-run economies of scale. This is shown in Figure 1 using a diagram similar to Figure 1 in Mogridge (1997). The distance between the vertical axes is equal to the total number of trips by auto and transit combined which is fixed in the standard model. The price of driving, $p_{a}\left(v_{a}, s\right)$, is measured to the right from the left-hand axis, and the price of transit, $p_{b}\left(v_{b}\right)$, is measured to the left from the right-hand axis. With initial highway capacity of $s$, an equilibrium is reached at point $E$ and the common price of travel is $p_{E}$. If capacity is expanded to $s^{\prime}$, curve $p_{a}\left(v_{a}, \mathrm{~s}\right)$ pivots clockwise to $p_{a}\left(v_{a}, \mathrm{~s}^{\prime}\right)$, a new equilibrium is reached at point $E^{\prime}$, and the price of travel rises to $p_{E}^{\prime}$.

Insert Figure 1 here.

\footnotetext{
${ }^{5}$ Zhang et al. (2014) considered both marginal and discrete changes in highway capacity.
} 
Figure 1 is not applicable in the model here. With elastic total travel demand the distance between the two axes is not fixed, and with imperfect substitutes, prices $p_{a}$ and $p_{b}$ are not equal in equilibrium and their derivatives in Eq. (3) differ as well. To determine how the prices change we first derive the effect of highway expansion on prices.

According to Eqs. (1) and (2), the marginal changes in prices due to highway expansion are the sum of changes in monetary costs and travel time costs:

$$
\begin{aligned}
& \frac{d p_{a}}{d s}=\frac{\partial c_{a}}{\partial v_{a}} \frac{d v_{a}}{d s}+\frac{\partial c_{a}}{\partial s}, \\
& \frac{d p_{b}}{d s}=\frac{\partial c_{b}}{\partial v_{b}} \frac{d v_{b}}{d s}+\frac{\partial c_{b}}{\partial f} \frac{d f}{d s}+\frac{d \tau_{b}}{d s} .
\end{aligned}
$$

To characterize the combined effects of changes in service frequency and fare (the last two terms of Eq. (5)), define

$$
\delta \equiv \frac{\partial c_{b}}{\partial f} \frac{d f}{d s}+\frac{d \tau_{b}}{d s} .
$$

If $\delta<0$, the adjustment of transit service acts to reduce the price of transit, and if $\delta \geq 0$ it acts to increase the price. Since $\delta$ describes the direction and rate of transit service adjustment, it will be called the "Transit adjustment factor" or TAF for short.

Following Mohring (1972), much of the literature has considered a welfare-maximizing operator in charge of an isolated public transit system. The situation considered here differs in two respects. First, the highway offers a second mode of travel and the initial change in ridership is caused by a change in highway capacity. Second, depending on the operator's objective, it may or may not be concerned with the well-being of transit users or drivers. Hence, it is not clear a priori whether transit ridership and service quality move in tandem as in Mohring's original model, or whether they can change in opposite directions.

To investigate this question, we first examine the effects of highway expansion on travel volumes which are described by the following two expressions:

$$
\begin{aligned}
& \frac{d v_{a}}{d s}=\frac{\partial v_{a}}{\partial p_{a}} \frac{d p_{a}}{d s}+\frac{\partial v_{a}}{\partial p_{b}} \frac{d p_{b}}{d s}, \\
& \frac{d v_{b}}{d s}=\frac{\partial v_{b}}{\partial p_{b}} \frac{d p_{b}}{d s}+\frac{\partial v_{b}}{\partial p_{a}} \frac{d p_{a}}{d s} .
\end{aligned}
$$

The first term in each expression captures own-price effects on demand, and the second term captures cross-price effects. Substituting Eqs. (7) and (8) into (4) and (5) we have

$$
\left(1-\frac{\partial c_{a}}{\partial v_{a}} \frac{\partial v_{a}}{\partial p_{a}}\right) \frac{d p_{a}}{d s}=\frac{\partial c_{a}}{\partial v_{a}} \frac{\partial v_{a}}{\partial p_{b}} \frac{d p_{b}}{d s}+\frac{\partial c_{a}}{\partial s},
$$




$$
\begin{aligned}
& \frac{d p_{a}}{d s}=\frac{1}{\theta}\left[\left(1-\frac{\partial c_{b}}{\partial v_{b}} \frac{\partial v_{b}}{\partial p_{b}}\right) \frac{\partial c_{a}}{\partial s}+\frac{\partial c_{a}}{\partial v_{a}} \frac{\partial v_{a}}{\partial p_{b}} \delta\right], \\
& \frac{d p_{b}}{d s}=\frac{1}{\theta}\left[\left(1-\frac{\partial c_{a}}{\partial v_{a}} \frac{\partial v_{a}}{\partial p_{a}}\right) \delta+\frac{\partial c_{b}}{\partial v_{b}} \frac{\partial v_{b}}{\partial p_{a}} \cdot \frac{\partial c_{a}}{\partial s}\right],
\end{aligned}
$$

where $\theta \equiv 1-\frac{\partial c_{a}}{\partial v_{a}} \frac{\partial v_{a}}{\partial p_{a}}-\frac{\partial c_{b}}{\partial v_{b}} \frac{\partial v_{b}}{\partial p_{b}}+\frac{\partial c_{a}}{\partial v_{a}} \frac{\partial c_{b}}{\partial v_{b}}\left(\frac{\partial v_{a}}{\partial p_{a}} \frac{\partial v_{b}}{\partial p_{b}}-\frac{\partial v_{a}}{\partial p_{b}} \frac{\partial v_{b}}{\partial p_{a}}\right)>0$. Eqs. (10) and (11) show that the changes in prices depend on the size of the TAF. Define $\delta_{p_{a}} \equiv-\frac{\partial c_{a}}{\partial s}\left(1-\frac{\partial c_{b}}{\partial v_{b}} \frac{\partial v_{b}}{\partial p_{b}}\right) /\left(\frac{\partial c_{a}}{\partial v_{a}} \frac{\partial v_{a}}{\partial p_{b}}\right)>0$ and $\delta_{p_{b}} \equiv-\frac{\partial c_{a}}{\partial s} \frac{\partial c_{b}}{\partial v_{b}} \frac{\partial v_{b}}{\partial p_{a}} /\left(1-\frac{\partial c_{a}}{\partial v_{a}} \frac{\partial v_{a}}{\partial p_{a}}\right)>0$ where $0<\delta_{p_{b}}<\delta_{p_{a}}$. These two quantities are critical values of the TAF as explained in the following proposition:

Proposition 1. Following a marginal increase of highway capacity:

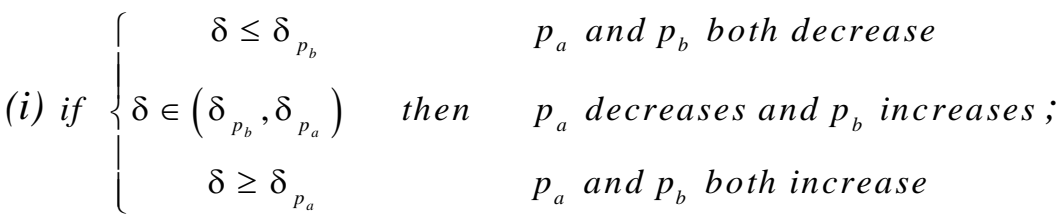

(ii) if $p_{b}$ decreases then $p_{a}$ also decreases; if $p_{a}$ increases then $p_{b}$ also increases.

Proof. The proof is given in Appendix A.1.

Proposition 1(i) describes the relation between transit responses and changes in prices by identifying intervals of the TAF in which the prices both decrease, both increase, or change in opposite directions. The boundaries of the three intervals depend on the slopes of the demand and user cost functions.

As expected, both prices decrease if transit service is improved $(\delta<0)$ when highway capacity expands. But even if transit service deteriorates, within the interval $\delta \in\left(0, \delta_{p_{b}}\right)$ both prices still fall. Thus, when the two modes are imperfect substitutes the price of transit can decline even if service is not improved. However, if $\delta>\delta_{p_{b}}$ service quality declines enough that the transit price rises. And if service deteriorates so much that $\delta>\delta_{p_{a}}$, prices for both modes increase. The strong D-T paradox then occurs if transit profits do not rise.

In the intermediate range of the TAF with $\delta \in\left(\delta_{p_{b}}, \delta_{p_{a}}\right)$, the price of transit rises and some users switch to driving. Nevertheless, highway usage does not increase by enough to offset the direct effect of greater capacity in reducing congestion and the price of driving falls. The two prices thus move in opposite directions. 
Proposition 1(ii) establishes that drivers are more likely than transit riders to benefit from highway expansion since the price of transit decreases only if (but not necessarily if) the price of driving falls. This is not surprising since the process of adjustment is led off by an increase in highway capacity that directly reduces highway travel time.

Changes in traffic volumes are solved by substituting Eqs. (10) and (11) into Eqs. (7) and (8):

$$
\begin{aligned}
& \frac{d v_{a}}{d s}=\frac{1}{\theta}\left[\frac{\partial v_{a}}{\partial p_{b}} \delta+\frac{\partial c_{a}}{\partial s}\left(\frac{\partial v_{a}}{\partial p_{a}}-\frac{\partial c_{b}}{\partial v_{b}}\left(\frac{\partial v_{a}}{\partial p_{a}} \frac{\partial v_{b}}{\partial p_{b}}-\frac{\partial v_{a}}{\partial p_{b}} \frac{\partial v_{b}}{\partial p_{a}}\right)\right)\right], \\
& \frac{d v_{b}}{d s}=\frac{1}{\theta}\left[\left(\frac{\partial v_{b}}{\partial p_{b}}-\frac{\partial c_{a}}{\partial v_{a}}\left(\frac{\partial v_{a}}{\partial p_{a}} \frac{\partial v_{b}}{\partial p_{b}}-\frac{\partial v_{a}}{\partial p_{b}} \frac{\partial v_{b}}{\partial p_{a}}\right)\right) \delta+\frac{\partial c_{a}}{\partial s} \frac{\partial v_{b}}{\partial p_{a}}\right] .
\end{aligned}
$$

Similar to the case with prices, the induced changes in travel volumes also depend on the TAF. The critical values work out to be $\delta_{v_{a}} \equiv-\frac{\partial c_{a}}{\partial s}\left[\frac{\partial v_{a}}{\partial p_{a}}-\frac{\partial c_{b}}{\partial v_{b}}\left(\frac{\partial v_{a}}{\partial p_{a}} \frac{\partial v_{b}}{\partial p_{b}}-\frac{\partial v_{a}}{\partial p_{b}} \frac{\partial v_{b}}{\partial p_{a}}\right)\right] / \frac{\partial v_{a}}{\partial p_{b}} \quad$ and $\delta_{v_{b}} \equiv-\frac{\partial c_{a}}{\partial s} \frac{\partial v_{b}}{\partial p_{a}} /\left[\frac{\partial v_{b}}{\partial p_{b}}-\frac{\partial c_{a}}{\partial v_{a}}\left(\frac{\partial v_{a}}{\partial p_{a}} \frac{\partial v_{b}}{\partial p_{b}}-\frac{\partial v_{a}}{\partial p_{b}} \frac{\partial v_{b}}{\partial p_{a}}\right)\right]$ where $0>\delta_{v_{b}}>\delta_{v_{a}}:$

Proposition 2. Following a marginal increase of highway capacity:

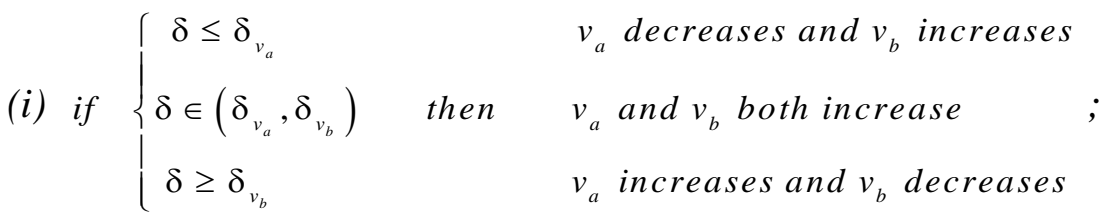

(ii) if $v_{a}$ decreases then $v_{b}$ increases; if $v_{b}$ decreases then $v_{a}$ increases.

Proof. The proof is given in Appendix A.2.

Proposition 2(i) establishes intervals of the TAF in which usage of each mode increases or decreases. Similar to Proposition 1, the boundaries of the intervals depend on the slopes of the demand and user cost functions. Transit ridership rises if the transit price falls enough; i.e. if $\delta \leq \delta_{v_{b}}$. If $\delta \leq \delta_{v_{a}}$, so that the transit price falls even more, auto traffic declines despite the increase in highway capacity. In the intermediate range $\delta \in\left(\delta_{v_{a}}, \delta_{v_{b}}\right)$, usage of both modes increases. If the TAF exceeds $\delta_{v_{b}}$, auto usage increases but transit usage declines. Since $\delta_{v_{b}}<0$, transit usage can drop despite a modest improvement in service. As Proposition 2(ii) indicates, for all values of the TAF usage of at least one mode increases. Thus, highway expansion cannot lead, perversely, to a reduction in travel by both modes.

Table 1 summarizes the directions in which prices and volumes change in different intervals of 
the TAF. The strong version of the D-T paradox can occur only in the last column with $\delta>\delta_{p_{a}}$ when transit service deteriorates severely. Note that each variable changes in the same direction in intervals $\left(\delta_{v_{b}}, 0\right)$ and $\left(0, \delta_{p_{b}}\right)$.

Insert Table 1 here.

One of the differences between this paper and Zhang et al. (2014) is that public transit crowding is considered. If crowding were omitted, then $\partial c_{b} / \partial v_{b}=0$, and the critical values of the TAF would simplify to: $\delta_{p_{a}}^{\prime}=-\frac{\partial c_{a}}{\partial s} / \frac{\partial c_{a}}{\partial v_{a}} \frac{\partial v_{a}}{\partial p_{b}}, \delta_{p_{b}}^{\prime}=0, \delta_{v_{a}}^{\prime}=-\frac{\partial c_{a}}{\partial s} \frac{\partial v_{a}}{\partial p_{a}} / \frac{\partial v_{a}}{\partial p_{b}}, \delta_{v_{b}}^{\prime}=\delta_{v_{b}}$. The interval $\left(0, \delta_{p_{b}}\right)$ disappears, and it is no longer possible for the transit price to fall if $\delta>0$. However, while the critical values change, the general results described in Propositions 1 and 2 remain valid and so does the summary in Table 1 .

Another difference between this paper and Zhang et al. (2014) is that total travel demand is elastic. If demand were totally inelastic, the interval $\left(\delta_{v_{a}}, \delta_{v_{b}}\right)$ would disappear and it would be impossible for both auto and transit trips to increase. Other than for this, however, Propositions 1 and 2 and Table 1 again remain intact.

Propositions 1 and 2 hold under general assumptions about the demand and user cost functions. The model also places no restriction on transit operating policy (e.g. social welfare or profit maximization). Alternative objectives for the transit operator are examined in the next section.

Now we explore the effect of highway expansion on overall social welfare. Let $C S$ denote Marshallian consumers' surplus. Because consumers' surplus is measured by the area under the demand curve, the partial derivative of consumers' surplus with respect to $p_{i}$ equals $-v_{i}$ (see, e.g., Varian, 1992):

$$
\frac{\partial C S}{\partial p_{i}}=-v_{i}, \quad i=a, b .
$$

Since the highway is toll-free, the only profit to consider is the transit operator's profit, $\pi$, which is equal to:

$$
\pi=\tau_{b} v_{b}-K(f) .
$$

In Eq. (15), $\tau_{b} v_{b}$ is fare revenue, and $K(f)$ is the construction and operating cost for a service with frequency $f$. Social welfare (total system benefit) will be measured by social surplus which is the sum of consumers' surplus and profit:

$$
S W=C S+\pi .
$$


To identify how much of the potential benefit from road expansion gets dissipated by changes in travelers' behavior we first consider the case in which transit service is absent and driving is the only option. Given a demand curve for car travel $v_{a}=v_{a}\left(p_{a}\right)$, the marginal social benefit of road capacity expansion is:

$$
M S W_{0}=v_{a} \cdot\left(-\frac{\partial c_{a}}{\partial s}\right)-\frac{d v_{a}}{d s} \cdot\left(v_{a} \frac{\partial c_{a}}{\partial v_{a}}\right) .
$$

The first term on the RHS of Eq. (17) is the direct marginal benefit from the road expansion, and the second term is the indirect marginal cost which equals the induced travel demand multiplied by the marginal cost of an additional driver. The weak version of the D-T paradox occurs if the indirect cost exceeds the direct benefit. This is consistent with the analytical results of Arnott and Yan (2000) who also provided a graphic illustration. Using homogeneity degree zero of the user cost function $c_{a}\left(v_{a}, \mathrm{~s}\right)$, Eq. (17) can be written

$$
M S W_{0}=\{1-\underbrace{\frac{d v_{a}}{d s} \frac{s}{v_{a}}}_{\eta_{a s}}) \cdot \frac{v_{a}}{s} \cdot\left(\frac{\partial c_{a}}{\partial v_{a}} v_{a}\right),
$$

where $\eta_{a s} \geq 0$ is the (equilibrium) elasticity of car usage with respect to road capacity. With no induced demand, $\eta_{a s}=0$ and the first term in brackets is 1 . By contrast, if induced demand is so strong that traffic volume rises in proportion to road capacity, then $\eta_{a s}=1$, the first term in brackets is zero, and the road expansion yields no benefit.

When transit service does exist, social welfare in Eq. (16) includes the consumers' surplus of both car and transit users as well as the transit operator's profit. Define $\gamma_{a} \equiv \frac{\partial c_{a}}{\partial v_{a}}\left(\frac{\partial v_{a}}{\partial p_{a}} \frac{\partial v_{b}}{\partial p_{b}}-\frac{\partial v_{a}}{\partial p_{b}} \frac{\partial v_{b}}{\partial p_{a}}\right)-\frac{\partial v_{b}}{\partial p_{b}}$. The marginal social benefit of capacity expansion can be written:

$$
M S W_{1}=v_{a} \cdot\left(-\frac{\partial c_{a}}{\partial s}\right)-\frac{d v_{a}}{d s} \cdot\left(v_{a} \frac{\partial c_{a}}{\partial v_{a}}\right)-\frac{d v_{b}}{d s} \cdot\left(v_{b} \frac{\partial c_{b}}{\partial v_{b}}-\tau_{b}\right)+J(\delta)
$$

where $J(\delta) \equiv\left\lceil\left(v_{b} \frac{\partial v_{a}}{\partial p_{a}}-v_{a} \frac{\partial v_{a}}{\partial p_{b}}\right) \frac{\partial c_{a}}{\partial v_{a}}-v_{b}-\tau_{b} \gamma_{a}\right] \frac{\delta}{\theta}+v_{b} \frac{d \tau_{b}}{d s}-K^{\prime} \frac{d f}{d s}$ denotes the marginal benefit from adjusting transit service. In Section 4 we will consider transit adjustments in various administration regimes. Here we examine the short run in which transit service remains constant so that $J(\delta)=0$. Eq. (19) reduces to:

$$
M S W_{1}^{\prime}=\underbrace{v_{a} \cdot\left(-\frac{\partial c_{a}}{\partial s}\right)-\underbrace{\frac{d v_{a}}{d s}}_{-\underline{d s}} \cdot\left(v_{a} \frac{\partial c_{a}}{\partial v_{a}}\right)}_{M S W_{0}}-\frac{d v_{b}}{d s} \cdot\left(\frac{\partial c_{b}}{\partial v_{b}} v_{b}-\tau_{b}\right)
$$


The first two terms on the RHS of Eq. (20) equal $M S W_{0}$. The third term is the indirect marginal cost of changes in transit ridership which equals the induced transit trips multiplied by the net social cost of an additional user. Using Eq. (18), Eq. (20) can be written

$$
M S W_{1}^{\prime}=(1-\underbrace{\frac{d v_{a}}{d s} \frac{s}{v_{a}}}_{\eta_{a s}}) \cdot \frac{v_{a}}{s} \cdot\left(\frac{\partial c_{a}}{\partial v_{a}} v_{a}\right)-\underbrace{\frac{d v_{b}}{d s} \frac{s}{v_{b}}}_{\eta_{b s}} \cdot \frac{v_{b}}{s} \cdot\left(\frac{\partial c_{b}}{\partial v_{b}} v_{b}-\tau_{b}\right),
$$

where $\eta_{b s} \leq 0$ is the (equilibrium) elasticity of transit usage with respect to road capacity. If $\eta_{b s}<0$ and transit service is priced above marginal cost (i.e., $\tau_{b}>\frac{\partial c_{b}}{\partial v_{b}} v_{b}$ ), the last term in Eq. (21) is negative and the benefit from road expansion is dissipated not only by the increase in driving, but also the decrease in transit ridership. ${ }^{6}$ The last term is larger in magnitude: the larger the elasticity $\eta_{b s}$, the larger is transit usage $v_{b}$, the higher the fare $\tau_{b}$, and the lower the incremental operating and crowding cost caused by an additional passenger $\left(\partial c_{b} / \partial v_{b}\right) v_{b}$.

\section{Transit operator's responses to highway expansion under different regimes}

Section 3 establishes that the effects of highway expansion depend on how the transit operator responds. The operator's response depends on its goals. In this section we consider three goals: (a) profit maximization, (b) social welfare maximization, and (c) consumers' surplus maximization subject to a self-financing constraint. We treat highway capacity as exogenous and exclude construction and maintenance costs from consideration. The welfare effects of capacity expansion are therefore assessed without accounting for these costs. If measured welfare declines, so that the weak version of the D-T paradox occurs, then overall welfare declines by more if highway costs are deducted.

Despite the simplicity of the model, the analytics are quite tedious. To enhance tractability somewhat, it is henceforth assumed that the demand curves take the linear form:

$$
\begin{aligned}
& v_{a}=d_{0 a}-e_{1} p_{a}+e_{2} p_{b}, \\
& v_{b}=d_{0 b}-e_{1} p_{b}+e_{2} p_{a},
\end{aligned}
$$

where $e_{1}$ and $e_{2}$ are constants, and $e_{1}>e_{2} \geq 0$ (consistent with the requirement $\left.\frac{\partial v_{a}}{\partial p_{a}} \frac{\partial v_{b}}{\partial p_{b}}-\frac{\partial v_{a}}{\partial p_{b}} \frac{\partial v_{b}}{\partial p_{a}}>0\right)$. The utility function underlying Eqs. (22) and (23) is described in Appendix A.5. Own and cross-price elasticities of demand are

$$
\varepsilon_{a a}=\frac{\partial v_{a}}{\partial p_{a}} \frac{p_{a}}{v_{a}}=-e_{1} \frac{p_{a}}{v_{a}}, \varepsilon_{b b}=\frac{\partial v_{b}}{\partial p_{b}} \frac{p_{b}}{v_{b}}=-e_{1} \frac{p_{b}}{v_{b}}, \varepsilon_{a b}=\frac{\partial v_{a}}{\partial p_{b}} \frac{p_{b}}{v_{a}}=e_{2} \frac{p_{b}}{v_{a}}, \varepsilon_{b a}=\frac{\partial v_{b}}{\partial p_{a}} \frac{p_{a}}{v_{b}}=e_{2} \frac{p_{a}}{v_{b}} \text {. }
$$

\footnotetext{
${ }^{6}$ In their brief analysis of the D-T paradox, Arnott and Yan (2000) treat the full price of transit travel as a constant - thereby precluding transit crowding.
} 
Parameter $e_{1}$ governs the own-price elasticity of demand for each mode, and $e_{2}$ governs the cross-price elasticity. If $e_{2}=0$, demands for the two modes are independent. As $e_{2}$ increases, the modes become better substitutes. In the limit as $e_{2}$ approaches $e_{1}$, total travel demand is constant since $v_{a}+v_{b}=d_{0 a}+d_{0 b}$. However, even in the limit with $e_{2}=e_{1}$, the modes are not perfect substitutes and the model is not equivalent to the one in Zhang et al. (2014) because prices do not have to be equal in equilibrium. To see this, note that with $e_{2}=e_{1}$ demand for mode $i$ becomes $v_{i}=d_{0 i}-e_{1}\left(p_{i}-p_{j}\right), j \neq i$. Demand for each mode is a linear function of the difference in prices so that both modes can be used even if their prices differ. ${ }^{7}$ Only in the double limiting case with $e_{2}=e_{1} \rightarrow \infty$ are $p_{a}$ and $p_{b}$ necessarily equal in an (interior) equilibrium.

Eqs. (22) and (23) incorporate the assumption that the own-price coefficients are equal; i.e., $\partial v_{i} / \partial p_{i}=-e_{1}, i=a, b .{ }^{8}$ This assumption further simplifies analysis while still allowing mode shares, own-price elasticities, and cross-price elasticities all to differ. For the numerical experiments in Section 6, the values of $e_{1}$ and $e_{2}$ are calibrated from empirical estimates of price-elasticities. ${ }^{9}$

\subsection{Profit-maximizing transit policy}

Let superscript Prof denote the regime in which the transit operator maximizes its profit, given in Eq. (15). First-order conditions for the profit-maximizing frequency and fare, $f^{\text {Prof }}$ and $\tau_{b}^{\text {Prof }}$, are:

$$
\begin{aligned}
& f^{\text {Prof }}: \tau_{b} \frac{d v_{b}}{d f}=K^{\prime}, \\
& \tau_{b}^{\text {Prof }}: \tau_{b} \frac{d v_{b}}{d \tau_{b}}+v_{b}=0,
\end{aligned}
$$

where $K^{\prime} \equiv d K(f) / d f$. Eq. (24) prescribes that the marginal revenue from increasing frequency balances the marginal increase in cost. Eq. (25) stipulates that the marginal revenue from adjusting the fare is zero. Using the formulas for the derivatives given in Appendix A.1,

\footnotetext{
${ }^{7}$ Hotelling's (1929) model of spatial duopolistic competition also has this property.

${ }^{8}$ van den Berg (2013) also assumes symmetric marginal demands for different congestible facilities. Note that symmetry of the own/cross-price derivatives does not imply symmetry of the own/cross-price elasticities. Moreover, the demand intercepts, $d_{0 a}$ and $d_{0 b}$, the user cost functions, and equilibrium prices can all differ for the two modes.

${ }^{9}$ Note that assuming linearity of the demand curves is not restrictive as far as analyzing marginal changes in highway capacity since the comparative statics effects depend only on the slopes of the demand curves, not their curvature.
} 
and defining $\gamma_{a} \equiv e_{1}+\left(e_{1}^{2}-e_{2}^{2}\right) \frac{\partial c_{a}}{\partial v_{a}}$, the first-order conditions can be written as:

$$
\begin{aligned}
& -\frac{1}{\theta} \frac{\partial c_{b}}{\partial f} \tau_{b}\left(e_{1}+\left(e_{1}^{2}-e_{2}^{2}\right) \frac{\partial c_{a}}{\partial v_{a}}\right)-K^{\prime}=0 \Leftrightarrow K^{\prime}=-\frac{\gamma_{a}}{\theta} \frac{\partial c_{b}}{\partial f} \tau_{b}, \\
& -\frac{1}{\theta}\left(e_{1}+\left(e_{1}^{2}-e_{2}^{2}\right) \frac{\partial c_{a}}{\partial v_{a}}\right) \tau_{b}+v_{b}=0 \Leftrightarrow \tau_{b}=\frac{\theta v_{b}}{\gamma_{a}} .
\end{aligned}
$$

The second-order conditions require

$$
\Delta_{\text {Prof }} \equiv \frac{2 \theta}{\gamma_{a}}-\frac{e_{2}^{3} v_{b}}{\gamma_{a}^{3}} \frac{\partial^{2} c_{a}}{\partial v_{a}^{2}}+v_{b} \frac{\partial^{2} c_{b}}{\partial v_{b}^{2}}-\left(v_{b} \frac{\partial^{2} c_{b}}{\partial f \partial v_{b}}+\frac{\partial c_{b}}{\partial f}\right)^{2}\left(K^{\prime \prime}+v_{b} \frac{\partial^{2} c_{b}}{\partial f^{2}}\right)^{-1}>0 .
$$

When road capacity is expanded, the transit frequency and fare are incrementally adjusted in response to the loss of patronage. Then Eqs. (26) and (27) can be used to derive the TAF for the profit-maximizing operator:

$$
\delta^{\text {Prof }}=\frac{e_{2}}{\gamma_{a}} \frac{\partial c_{a}}{\partial s} \frac{\frac{\theta}{\gamma_{a}}-\frac{e_{2} \gamma_{b} v_{b}}{\gamma_{a}^{2}} \frac{\partial^{2} c_{a}}{\partial v_{a}^{2}}+v_{b} \frac{\partial^{2} c_{b}}{\partial v_{b}^{2}}-\left(\frac{\partial c_{b}}{\partial f}+v_{b} \frac{\partial^{2} c_{b}}{\partial f \partial v_{b}}\right)^{2}\left(K^{\prime \prime}+v_{b} \frac{\partial^{2} c_{b}}{\partial f^{2}}\right)^{-1}+\frac{e_{2} \theta v_{b}}{\gamma_{a}^{2}} \frac{\partial^{2} c_{a}}{\partial s \partial v_{a}}\left(\frac{\partial c_{a}}{\partial s}\right)^{-1}}{\Delta_{\text {Prof }}}
$$

where $\gamma_{b} \equiv e_{1}+\left(e_{1}^{2}-e_{2}^{2}\right) \frac{\partial c_{b}}{\partial v_{b}}$.

The effect of highway expansion on the operator's profit is described in the following proposition:

Proposition 3. When the transit operator maximizes profit, a marginal highway expansion reduces its profit.

Proof. By the envelope theorem, the effect of a change in highway capacity can be evaluated by taking the partial derivative of the profit function in Eq. (15) with respect to $s$ :

$$
\frac{d \pi}{d s}=\frac{\partial \pi}{\partial s}=\tau_{b} \frac{d v_{b}}{d s}=e_{2} \frac{v_{b}}{\gamma_{a}} \frac{\partial c_{a}}{\partial s}<0
$$

where the last equality follows from Eq. (27).

Proposition 3 establishes the intuitive result that the transit operator cannot avoid a profit loss when the service quality of a competing mode (the highway) improves. Since the operator is maximizing profit before the increase, it cannot offset the loss of ridership by adjusting either service frequency or fare. The operator still faces a trade-off between attracting users, and either increasing operating costs through an increase in service frequency or reducing its profit margin by lowering the fare. Zhang et al. (2014) showed that Proposition 3 holds when the two modes are perfect substitutes and system-wide demand is fixed. 


\subsection{Social welfare-maximizing transit policy}

Next, consider the regime, denoted by superscript $S W$, in which the transit operator maximizes social welfare as given by Eq. (16). The first-order conditions for the optimal frequency and fare, $f^{s W}$ and $\tau_{b}^{s W}$, are:

$$
\begin{aligned}
& f^{S W}: \tau_{b} \frac{d v_{b}}{d f}=v_{a} \frac{d p_{a}}{d f}+v_{b} \frac{d p_{b}}{d f}+K^{\prime}, \\
& \tau_{b}^{S W}: v_{b}+\tau_{b} \frac{d v_{b}}{d \tau_{b}}=v_{a} \frac{d p_{a}}{d \tau_{b}}+v_{b} \frac{d p_{b}}{d \tau_{b}} .
\end{aligned}
$$

The LHS of Eq. (30) is the marginal increase in fare revenue from expanding service frequency. The RHS is the net increase in cost. The first two terms on the RHS correspond to changes in full prices which are negative if the corresponding prices decrease. The third term is the marginal increase in capital and operating cost. Thus, Eq. (30) stipulates that the marginal revenue from increasing frequency balance the marginal cost. Similarly, Eq. (31) dictates that the fare be set to balance the operator's marginal revenue and the marginal cost to users. Using the formulas in Appendix A.1 for the derivatives, the first-order conditions can be written as:

$$
\begin{aligned}
& v_{a} e_{2} \frac{\partial c_{a}}{\partial v_{a}} \frac{\partial c_{b}}{\partial f}+v_{b}\left(1+e_{1} \frac{\partial c_{a}}{\partial v_{a}}\right) \frac{\partial c_{b}}{\partial f}+\gamma_{a} \tau_{b} \frac{\partial c_{b}}{\partial f}+\theta K^{\prime}=0, \\
& v_{a} e_{2} \frac{\partial c_{a}}{\partial v_{a}}+v_{b}\left(1+e_{1} \frac{\partial c_{a}}{\partial v_{a}}\right)+\gamma_{a} \tau_{b}-\theta v_{b}=0 .
\end{aligned}
$$

The second-order conditions require

$$
\Delta_{S W} \equiv e_{2}^{2}\left(\gamma_{a} \frac{\partial c_{a}}{\partial v_{a}}+e_{1} v_{a} \frac{\partial^{2} c_{a}}{\partial v_{a}^{2}}\right)+\gamma_{a}^{3}\left|v_{b} \frac{\partial^{2} c_{b}}{\partial v_{b}^{2}}+\frac{\partial c_{b}}{\partial v_{b}}-\frac{\left(\frac{\partial c_{b}}{\partial f}+v_{b} \frac{\partial^{2} c_{b}}{\partial f \partial v_{b}}\right)^{2}}{K^{\prime \prime}+v_{b} \frac{\partial^{2} c_{b}}{\partial f^{2}}}\right|+\theta \gamma_{a}^{2}>0 .
$$

The TAF for the social welfare-maximizing operator is derived from Eqs. (32) and (33):

$$
\delta^{S W}=e_{2} \frac{\gamma_{b} \frac{\partial c_{a}}{\partial s}\left(\gamma_{a} \frac{\partial c_{a}}{\partial v_{a}}+e_{1} v_{a} \frac{\partial^{2} c_{a}}{\partial v_{a}^{2}}\right)+\gamma_{a}^{2} \frac{\partial c_{a}}{\partial s} \mid v_{b} \frac{\partial^{2} c_{b}}{\partial v_{b}^{2}}+\frac{\partial c_{b}}{\partial v_{b}}-\frac{\left.\left(\frac{\partial c_{b}}{\partial f}+v_{b} \frac{\partial^{2} c_{b}}{\partial f \partial v_{b}}\right)^{2}\right)}{\left.K^{\prime \prime}+v_{b} \frac{\partial^{2} c_{b}}{\partial f^{2}}\right)^{2}}-\theta e_{1} v_{a} \frac{\partial^{2} c_{a}}{\partial s \partial v_{a}}}{\Delta_{S W}}
$$

The welfare effect of highway expansion on social welfare is presented in the following proposition: 
Proposition 4. When the transit operator maximizes social welfare, a marginal highway expansion increases social welfare.

Proof. According to Eqs. (32) and (33), at the optimum,

$$
K^{\prime}=-v_{b} \frac{\partial c_{b}}{\partial f} .
$$

By the envelope theorem, the effect of a change in capacity on social welfare can be evaluated using the partial derivative of the social welfare function in Eq. (16) with respect to $s$ :

$$
\begin{aligned}
& \frac{d S W}{d s}=\frac{\partial S W}{\partial s}=-v_{a} \frac{d p_{a}}{d s}-v_{b} \frac{d p_{b}}{d s}+\tau_{b} \frac{d v_{b}}{d s}+v_{b} \frac{d \tau_{b}}{d s}-K^{\prime} \frac{d f}{d s} \\
& =-\frac{\left(\left(1+e_{1} \frac{\partial c_{b}}{\partial v_{b}}\right) \gamma_{a}+e_{2}^{2} \frac{\partial c_{a}}{\partial v_{a}}\right) v_{a}}{\theta \gamma_{a}} \frac{\partial c_{a}}{\partial s}>0,
\end{aligned}
$$

where the last equality follows from Eqs. (32), (33) and (36).

Proposition 4 shows that welfare increases when highway capacity is expanded. This is as expected since the expansion directly benefits drivers, and the transit operator can adjust service frequency and fare to re-optimize the modal split.

Nevertheless, Proposition 4 needs to be qualified in two respects. First, as noted above the cost of highway expansion is disregarded so there is no guarantee that expansion is welfareenhancing net of the cost. Second, an increase in aggregate welfare does not imply that every individual is better-off. Welfare includes the transit operator's profit, and it is possible that profits can increase at the expense of users. Furthermore, even if users in aggregate gain, transit users can be worse off (cf. the case $\delta_{p_{a}}>\delta^{S W}>\delta_{p_{b}}$ in Table 1).

\subsection{Consumers' surplus maximizing transit policy with a self-financing constraint}

The social-welfare-maximizing transit policy analyzed in the previous subsection may run a deficit - especially if transit has substantial scale economies. Indeed, most transit services worldwide are heavily subsidized. Nevertheless, transit operators often face pressure to cover a substantial portion of their costs from farebox revenues. In extreme cases, subsidies could be precluded for political or other reasons and the operator then has to be fully self-financing. Indeed, this is the standard case considered in the literature on the D-T paradox. When profits are zero, social surplus reduces to consumers' surplus, and the operator's objective effectively becomes one of maximizing the combined surplus of transit riders and drivers subject to a transit self-financing constraint.

To satisfy the self-financing constraint, the fare has to be set equal to average service cost so 
that $\tau_{b}=K / v_{b}$. The transit operator's problem is thus reduced to one of optimizing service frequency to maximize consumers' surplus, $C S$. Increasing frequency reduces users' cost, but the fare has to be raised to cover the added cost. Optimal frequency is determined at the point where consumers' surplus for transit users and drivers together is maximized. The first-order condition is

$$
f^{C S}:-v_{a} \frac{d p_{a}}{d f}-v_{b} \frac{d p_{b}}{d f}=0,
$$

where superscript $C S$ denotes the consumers' surplus-maximizing regime subject to a selffinancing constraint and

$$
\begin{aligned}
& \frac{d p_{a}}{d f}=\frac{e_{2} v_{b} \frac{\partial c_{a}}{\partial v_{a}}\left(K^{\prime}+v_{b} \frac{\partial c_{b}}{\partial f}\right)}{\theta v_{b}^{2}-\gamma_{a} K}, \\
& \frac{d p_{b}}{d f}=\frac{v_{b}\left(1+e_{1} \frac{\partial c_{a}}{\partial v_{a}}\right)\left(K^{\prime}+v_{b} \frac{\partial c_{b}}{\partial f}\right)}{\theta v_{b}^{2}-\gamma_{a} K} .
\end{aligned}
$$

Substituting Eqs. (39) and (40) into (38) yields

$$
\left(K^{\prime}+v_{b} \frac{\partial c_{b}}{\partial f}\right)\left(e_{2} v_{a}^{2} \frac{\partial c_{a}}{\partial v_{a}}+v_{b}^{2}\left(1+e_{1} \frac{\partial c_{a}}{\partial v_{a}}\right)\right) v_{b}=0 \Leftrightarrow K^{\prime}+v_{b} \frac{\partial c_{b}}{\partial f}=0 .
$$

The second-order condition is

$$
-K^{\prime \prime} v_{b}\left(\theta v_{b}^{2}-\gamma_{a} K\right)^{-1}\left(e_{2} v_{a} \frac{\partial c_{a}}{\partial v_{a}}+\left(1+e_{1} \frac{\partial c_{a}}{\partial v_{a}}\right) v_{b}\right)<0 \Leftrightarrow \Delta_{C S} \equiv \theta v_{b}^{2}-\gamma_{a} K>0,
$$

The TAF for the operator in this regime is derived from Eq. (41):

$$
\delta^{C S}=-\frac{e_{2} K}{\Delta_{C S}} \frac{\partial c_{a}}{\partial s} \text {. }
$$

The effect of highway expansion on the operator's policy is summarized in the following proposition:

Proposition 5. When the transit operator maximizes consumers' surplus subject to a selffinancing constraint, and highway capacity is expanded marginally, then:

(i) transit service deteriorates, i.e., $\delta^{C S}>0$;

(ii) auto traffic rises and transit ridership declines.

Proof. (i) By assumption, $\partial c_{a} / \partial s<0$, and by the second-order condition in Eq. (42) the denominator of Eq. (43) is positive. Hence, when $e_{2} \neq 0$, Eq. (43) implies $\delta^{c S}>0$. Part (ii) follows from (i). 
According to Proposition 5(i), transit service deteriorates when the highway is improved. The operator is unable to sustain the existing service, let alone improve it. Because ridership drops, to continue covering costs the operator has to reduce service frequency, increase the fare, or do both. Hence $\delta^{C S}>0$, and some travelers switch from transit to driving as per Proposition 5(ii). Thus, in the self-financing regime transit ridership and service quality move in parallel as in Mohring's original model.

Proposition 5 is consistent with Zhang et al. (2014) who show that with perfectly substitutable modes, and fixed total demand, transit service deteriorates under a self-financing constraint. However, unlike in their model the D-T paradox is not inevitable. To conclude this section we explore under what conditions the weak version of the D-T paradox can occur. With profits constrained to zero, the change in social welfare in response to a marginal capacity expansion is

$$
\frac{d S W}{d s}=-v_{a} \frac{d p_{a}}{d s}-v_{b} \frac{d p_{b}}{d s} .
$$

Using Eqs. (10), (11) and (43) this can be written

$$
\frac{d S W}{d s}=-\frac{1}{\theta} \frac{\partial c_{a}}{\partial s}\left\{\begin{array}{l}
v_{a}\left(1-\frac{\partial c_{b}}{\partial v_{b}} \frac{\partial v_{b}}{\partial p_{b}}\right)-v_{a} \frac{\partial c_{a}}{\partial v_{a}} \frac{\partial v_{a}}{\partial p_{b}} \frac{e_{2} K}{\theta v_{b}^{2}-\gamma_{a} K} \\
-v_{b}\left(1-\frac{\partial c_{a}}{\partial v_{a}} \frac{\partial v_{a}}{\partial p_{a}}\right) \frac{e_{2} K}{\theta v_{b}^{2}-\gamma_{a} K}+v_{b} \frac{\partial c_{b}}{\partial v_{b}} \frac{\partial v_{b}}{\partial p_{a}}
\end{array}\right\} .
$$

With the demand functions in Eqs. (22) and (23) this expression becomes

$$
\frac{d S W}{d s}=-\frac{1}{\theta} \frac{\partial c_{a}}{\partial s}\left\{\begin{array}{c}
v_{a}\left(1+\frac{\partial c_{b}}{\partial v_{b}} e_{1}\right)-v_{a} \frac{\partial c_{a}}{\partial v_{a}} \frac{e_{2}^{2} K}{\theta v_{b}^{2}-\gamma_{a} K} \\
-v_{b}\left(1+\frac{\partial c_{a}}{\partial v_{a}} e_{1}\right) \frac{e_{2} K}{\theta v_{b}^{2}-\gamma_{a} K}+v_{b} \frac{\partial c_{b}}{\partial v_{b}} e_{2}
\end{array}\right\},
$$

or

$$
\frac{d S W}{d s}=-\frac{1}{\theta} \frac{\partial c_{a}}{\partial s}\{v_{a}+\underbrace{\frac{\partial c_{b}}{\partial v_{b}}\left(e_{1} v_{a}+e_{2} v_{b}\right)}_{(2)}-\underbrace{\frac{e_{2} K}{\theta v_{b}^{2}-\gamma_{a} K}}_{(3)} \underbrace{\left(\frac{\partial c_{a}}{\partial v_{a}}\left(e_{2} v_{a}+e_{1} v_{b}\right)+v_{b}\right)}_{(-1)}\} .
$$

Each of the four numbered terms in Eq. (44) is nonnegative. To begin, suppose that auto and transit demands are unrelated so that $e_{2}=0$. Term (3) is then zero, and welfare unambiguously increases. The composite variable $\theta$ reduces to $\theta=\left(1+e_{1}\left(\partial c_{a} / \partial v_{a}\right)\right)\left(1+e_{1}\left(\partial c_{b} / \partial v_{b}\right)\right)$, and Eq. (44) simplifies to

$$
\left.\frac{d S W}{d s}\right|_{e_{2}=0}=\frac{-v_{a}\left(\partial c_{a} / \partial s\right)}{1+e_{1}\left(\partial c_{a} / \partial v_{a}\right)} .
$$


The numerator of Eq. (45) is the aggregate reduction in drivers' user costs if the number of auto trips does not change. This amount is deflated by the denominator to account for latent demand; i.e. the increase in driving and partial rebound in congestion because travel time has fallen.

Consider now the case of main interest with $e_{2}>0$. Other things equal, welfare is more likely to increase when auto usage is high (term 1 in Eq. (44)). Many drivers then benefit directly from greater capacity. A welfare increase is also more likely when transit crowding is severe (i.e., $\partial c_{b} / \partial v_{b}$ in term 2 is large) since highway expansion helps to alleviate crowding. By contrast, welfare is more likely to decrease when $e_{2}$ is large since this boosts term (3). Welfare is also more likely to drop when the derivative $\partial c_{a} / \partial v_{a}$ in term (4) is large. This term measures the rate at which driving costs rise as individuals switch from transit to driving. It corresponds to the slope of the highway cost curve in Figure 1.

Term (3) in Eq. (44) is an increasing and convex function of the cost of transit frequency, $K$. To understand this dependence it is helpful to elaborate a bit on the model. Optimal frequency is determined by the first-order condition in Eq. (41): $K^{\prime}=-v_{b} \frac{\partial c_{b}}{\partial f}$. Let $\varepsilon_{K} \equiv K^{\prime} \frac{f}{K}$ denote the elasticity of the transit cost function. The first-order condition can then be written

$$
K=-\frac{v_{b}}{\varepsilon_{K}} \frac{\partial c_{b}}{\partial f} f
$$

Next, decompose the transit user cost function into three terms:

$$
c_{b}\left(v_{b}, f\right)=c_{b 0}+c_{b 1}\left(v_{b}, f\right)+c_{b 2}(f) .
$$

In Eq. (47), $c_{b 1}\left(v_{b}, f\right)$ is the cost of transit crowding, and $c_{b 2}(f)$ is the combined cost of waiting time and schedule delay. The first term, $c_{b 0}$, designates costs that do not depend on service frequency such as the time cost of accessing transit stations and in-vehicle travel under crowd-free conditions. Let $\eta_{c a p} \equiv\left\|\frac{\partial c_{b 1}}{\partial f} \frac{f}{c_{b 1}}\right\|$ denote the elasticity of crowding cost with respect to frequency, and $\eta_{\text {wait }} \equiv\left\|\frac{\partial c_{b 2}}{\partial f} \frac{f}{c_{b 2}}\right\|$ the corresponding elasticity for waiting time and schedule delay. Condition (46) can then be written as

$$
K=\frac{\eta_{c a p} c_{b 1}+\eta_{\text {wait }} c_{b 2}}{\varepsilon_{K}} v_{b} \text {. }
$$

Returning to Eq. (44) it is now evident that term (3) is larger, and the weak version of the D-T paradox correspondingly more likely to occur: (i) the more sensitive are transit crowding costs to service frequency; (ii) the more sensitive are waiting time and schedule delays to service frequency; (iii) the larger are crowding, waiting time, and schedule delay costs as fractions of total transit user cost; (iv) the lower is the marginal cost of expanding frequency (i.e., the 
smaller is $\varepsilon_{K}$ ); and (v) the larger is total transit usage. All these effects accord with intuition. Factors (i)-(iii) contribute to scale economies in transit service for users, and (iv) reflects scale economies of supply. Factor (v) arises because, by Proposition 1, transit users are less likely than drivers to benefit from more highway capacity. The larger the number of transit users, the more likely that total traveler welfare falls.

\section{The model with linear transit operator and user cost functions}

To proceed with the analysis further we now adopt linear functions for the transit supply and user costs of the two modes. The transit investment and operating cost function is assumed to be $K(f)=k f, k>0$, so that $\varepsilon_{K}=1 .{ }^{10}$ The travel cost functions in Eqs. (1) and (2) have the functional forms:

$$
\begin{aligned}
& c_{a}\left(v_{a}, \mathrm{~s}\right)=c_{a 0}+c_{a 1} \frac{v_{a}}{s}=c_{a 0}+\sigma v_{a}, \\
& c_{b}\left(v_{b}, f\right)=c_{b 0}+c_{b 1} \frac{v_{b}}{f}+\frac{c_{b 2}}{f} .
\end{aligned}
$$

In Eq. (49), $c_{a 0}$ is the trip cost by automobile under free-flow conditions. The second term is the additional cost due to congestion which is assumed to be proportional to traffic volume $v_{a}$, and inversely proportional to highway capacity, $s$, so that $c_{a}\left(v_{a}, \mathrm{~s}\right)$ is homogeneous of degree zero in $v_{a}$ and $s$. To economize on notation, the ratio $c_{a 1} / s$ is written as $\sigma$.

Eq. (50) is a linear version of Eq. (47). The crowding cost component is homogeneous of degree zero in $v_{b}$ and $f$, and thus has a elasticity with respect to frequency of $\eta_{c a p}=1$. Expected waiting time and schedule delay cost is inversely proportional to frequency so that $\eta_{\text {wait }}=1$ and service is characterized by economies of traffic density as in Mohring's (1972) model.

Given Eqs. (49) and (50), $\gamma_{a}=e_{1}+\left(e_{1}^{2}-e_{2}^{2}\right) \sigma$ and $\theta=1+e_{1} \sigma+\gamma_{a} \frac{c_{b 1}}{f}$. To economize on writing, define the composite parameters $g_{a} \equiv d_{a 0}-e_{1}\left(\tau_{a}+c_{a 0}\right)+e_{2} c_{b 0}$ and $g_{b} \equiv d_{b 0}-e_{1} c_{b 0}+e_{2}\left(\tau_{a}+c_{a 0}\right)$. Substituting Eqs. (49) and (50) into Eqs. (1) and (2), then Eqs. (1) and (2) into Eqs. (22) and (23), and solving the two-equation system, yields for the number of trips by each mode

$$
v_{a}=\frac{1}{\theta}\left[\left(1+e_{1} \frac{c_{b 1}}{f}\right) g_{a}+\frac{e_{2} c_{b 1}}{f} g_{b}+e_{2}\left(\tau_{b}+\frac{c_{b 2}}{f}\right)\right],
$$

\footnotetext{
${ }^{10}$ Basso and Jara-Díaz (2012) also adopt this assumption.
} 


$$
v_{b}=\frac{1}{\theta}\left[e_{2} \sigma g_{a}+\left(1+e_{1} \sigma\right) g_{b}-\gamma_{a}\left(\tau_{b}+\frac{c_{b 2}}{f}\right)\right] .
$$

\subsection{Profit-maximizing transit policy with linear costs}

With the linear functions, the first-order conditions Eqs. (24) and (25) for the profitmaximizing fare and frequency become

$$
\begin{aligned}
& \tau_{b}^{\text {Prof }}=\frac{\theta}{\gamma_{a}} v_{b}=\frac{1+e_{1} \frac{\partial c_{a}}{\partial v_{a}}+\left(e_{1}+\left(e_{1}^{2}-e_{2}^{2}\right) \frac{\partial c_{a}}{\partial v_{a}}\right) \frac{\partial c_{b}}{\partial v_{b}}}{e_{1}+\left(e_{1}^{2}-e_{2}^{2}\right) \frac{\partial c_{a}}{\partial v_{a}}} v_{b}, \\
& f^{\text {Prof }}=\sqrt{\frac{\left(c_{b 2}+c_{b 1} v_{b}\right) v_{b}}{k}} .
\end{aligned}
$$

According to Eq. (53), the private operator sets a fare that is an increasing function of $v_{b}$ and a decreasing function of $e_{1}$. This is because the absolute price elasticity of demand for transit trips is a decreasing function of the number of trips, $v_{b}$, and an increasing function of parameter $e_{1}$. The fare is an increasing function of transit crowding as measured by the derivative $\partial c_{b} / \partial v_{b}$ because the operator internalizes the cost of crowding borne by users. If transit and auto trips were independent, so that $e_{2}=0$, the fare would be independent of road congestion, $\partial c_{a} / \partial v_{a}$. With $e_{2}>0$, the fare is an increasing function of $\partial c_{a} / \partial v_{a}$ because congestion makes driving a less effective substitute for transit. With $v_{b}$ held fixed, the fare is also an increasing function of $e_{2}$ provided $\partial c_{b} / \partial v_{b}>0$.

According to Eq. (54), the private operator chooses a service frequency that rises with ridership. However, with $c_{b 2}>0$ the dependence is less than proportional because waiting time and schedule delay costs do not depend on ridership, and the benefit from increasing frequency is subject to diminishing returns.

Solving Eqs. (52), (53) and (54) simultaneously for $v_{b}, \tau_{b}^{\text {Prof }}$ and $f^{\text {Prof }}$ yields a cubic equation for $f^{\text {Prof }}$ that does not simplify with either $c_{b 1}=0$ or $e_{2}=e_{1}$. With $c_{b 2}=0$, however, the transit system has constant economies of traffic density and a closed-form solution exists. Although this case rules out the D-T paradox, it is instructive to consider because the solution has most of the same properties as the case with $c_{b 2}>0$. To save space in the text, the solution with $c_{b 2}=0$ is provided in Appendix A.6. It is straightforward to show that if highway capacity increases, so that composite parameter $\sigma$ decreases, $\tau_{b}^{\text {Prof }}, f^{\text {Prof }}, p_{a}, p_{b}$ and $v_{b}$ all decrease, 
while $v_{a}$ increases. These comparative statics properties are recorded for the profitmaximization and other two regimes in Table 2.

\subsection{Social welfare-maximizing transit policy with linear costs}

The first-order conditions Eqs. (30) and (31) for the social welfare-maximizing fare and frequency yield

$$
\begin{aligned}
\tau_{b}^{S W} & =c_{b 1} \frac{v_{b}}{f}-\frac{e_{2} \sigma}{\gamma_{a}} v_{a}, \\
f^{S W} & =\sqrt{\frac{\left(c_{b 2}+c_{b 1} v_{b}\right) v_{b}}{k}} .
\end{aligned}
$$

In contrast to the profit-maximizing fare in Eq. (53), the welfare-maximizing fare in Eq. (55) has two terms. The first term is a Pigouvian tax on transit crowding. It matches the crowding component of the transit user cost function in Eq. (50) because, with linear crowding costs, the external cost of an additional rider is equal to the private crowding cost. The second term in Eq. (55) is a second-best adjustment to control for uninternalized traffic congestion. It is negative, and larger in magnitude the greater the substitutability between auto and transit (i.e., the larger is $e_{2}$ ) and the more severe is traffic congestion (i.e., the larger are $\sigma$ and $v_{a}$ ).

The optimal frequency rule in Eq. (56) is the same as for the profit-maximizing regime in Eq. (54). The rules are the same because in both cases the transit operator chooses frequency to minimize the sum of user costs and capacity costs. ${ }^{11}$

With $c_{b 2}=0$, there is a closed-form solution; see Appendix A.6. It is straightforward to show that if highway capacity increases, so that composite parameter $\sigma$ decreases, then $f^{S W}, p_{a}$, and $v_{b}$ decrease, while $v_{a}$ increases (see Table 2). The optimal fare, $\tau_{b}^{s w}$, and transit price, $p_{b}$, have a U-shaped dependence on capacity and reach a minimum with $s=c_{a 1} \sqrt{e_{1}^{2}-e_{2}^{2}}$. To see why, note that if capacity is very small few travelers use the highway and their welfare carries little weight in determining optimal transit policy. As highway capacity expands, the weight increases. Since the highway is congested, the operator has an incentive to decrease the fare in order to discourage driving. Once capacity increases enough, congestion becomes less severe and the incentive to keep the fare low diminishes. If capacity becomes so high that congestion becomes negligible, the need for second-best pricing of transit disappears and the fare is set as if transit were the only mode available; i.e. $\tau_{b}^{s W}=c_{b 1} v_{b} / f$.

\footnotetext{
${ }^{11}$ The rules would differ if users differed in their valuation of service quality. See Small and Verhoef (2007, $\S 6.1 .3)$.
} 


\subsection{Consumers' surplus-maximizing transit policy with a self-financing constraint and linear} costs

If the self-financing constraint is binding, the transit authority sets the fare to cover costs so that

$$
\tau_{b}^{C S}=\frac{K(f)}{v_{b}}=\frac{k f}{v_{b}} .
$$

The optimality condition for service frequency is the same as for the other two regimes:

$$
f^{C S}=\sqrt{\frac{\left(c_{b 2}+c_{b 1} v_{b}\right) v_{b}}{k}} .
$$

The closed-form solution with $c_{b 2}=0$ is recorded in Appendix A.6. It is straightforward to show that if highway capacity increases, $f^{C S}, p_{a}$, and $v_{b}$ decrease, $v_{a}$ increases, and $\tau_{b}^{C S}$ and $p_{b}$ do not change as shown in Table 2.

Insert Table 2 here.

\section{Numerical examples}

We now turn to numerical examples to explore the quantitative effects of highway capacity expansion in the profit maximization, social-welfare maximization, and self-financing transit regimes. In contrast to the analytical treatment in earlier sections, which is limited to marginal highway capacity changes, the numerical analysis is conducted over a wide range of capacity levels. Subsection 6.1 compares the three regimes. Subsection 6.2 focuses on occurrence of the D-T paradox in the self-financing regime.

\subsection{Transit operator responses to highway expansion}

The functional forms and base-case parameter values for the examples are listed in Table 3. The auto travel time cost function is assumed to have the BPR (Bureau of Public Roads) form (Sheffi, 1985), which is homogeneous of degree zero in traffic volume $v_{a}$ and highway capacity $s$. The transit user cost function has the same form as in Eq. (50). Parameter values are explained in Appendix A.7.

Insert Table 3 here.

The numerical analysis is conducted by setting highway capacity to a nominal starting value of $2000 \mathrm{veh} / \mathrm{h}$, and then increasing it progressively to $6000 \mathrm{veh} / \mathrm{h}$. This range roughly encompasses highways with 1-3 lanes in each direction. To economize on writing we now refer to the profit 
maximization, social-welfare maximization, and consumers'-surplus maximizing subject to self-financing regimes as Prof, $S W$, and $C S$ respectively.

Figure 2 shows the optimal combinations of frequency and fare at the initial capacity of $2000 \mathrm{veh} / \mathrm{h}$. The magenta, green, and red curves are respectively contour plots of transit profit, social welfare, and consumers' surplus in the frequency-fare domain. The magenta and green stars respectively identify the optima for regimes Prof and $S W$. For regime $C S$, the optimum occurs at the tangency, marked by the red star, between the zero-profit line (in blue) and the highest attainable consumers' surplus contour. Not surprisingly, of the three regimes Prof has the lowest frequency (22.43 run/hr) and the highest fare (107.39 HK\$). Regime $S W$ offers the highest frequency and the lowest fare, and operates at a loss since the green star lies outside the zero-profit contour. The optimal fare is positive, since it serves as a Pigouvian charge to internalize crowding costs on transit, but it is set below its first-best level in order to alleviate congestion on the highway as per Eq. (55).

\section{Insert Figure 2 here.}

Table 4 compares the three regimes with highway capacity set to 2000veh/h. Regime Prof has by far the lowest frequency, highest fare, and highest price for transit trips. Consequently, transit volume is much lower than in the other regimes and auto volume is slightly higher. Regime $S W$ has the highest frequency, lowest fare, and lowest prices for both modes. By all metrics, regime $C S$ is intermediate between the other two regimes, but it is much closer to regime $S W$ in terms of welfare so that the cost-recovery constraint is not too severe.

\section{Insert Table 4 here.}

Figure 3 shows how transit service adjusts as highway capacity expands. The first column of Figure 3 displays service frequency and fare. As capacity increases, both frequency and fare decrease in regime Prof. By contrast, in regimes $S W$ and $C S$ the fare rises so that the direction of movement is north-west rather than south-west. ${ }^{12}$ The small circles identify frequency and fare values as highway capacity increases in increments of $500 \mathrm{veh} / \mathrm{h}$. As capacity grows, its marginal effect diminishes and the circles get closer together.

The second column of Figure 3 depicts the evolution of transit price. Consistent with the changes in fares shown in the first column, transit price decreases in regime Prof and increases in regimes $S W$ and $C S$. The last column of Figure 3 displays the TAF. In regime Prof, the TAF, $\delta^{\text {Prof }}$, satisfies $\delta_{v_{b}}<\delta^{\text {Prof }}<0<\delta_{p_{b}}$. The operator therefore improves service, but not enough

\footnotetext{
${ }^{12}$ Recall that in regime $S W$, beyond some threshold level of highway capacity the transit operator raises the fare as capacity rises because traffic congestion becomes less acute, and the incentive to draw travelers out of their cars diminishes.
} 
to prevent a decline in ridership. In regime $S W, 0<\delta_{p_{b}}<\delta^{S W}<\delta_{p_{a}}$. Service deteriorates enough that the transit price rises, but not enough for the price of auto trips to rise too. Finally, in regime $C S, \delta_{v_{b}}<0<\delta^{C S}<\delta_{p_{b}}$. Service deteriorates, but the transit price still falls because of reduced crowding costs. Since the values of $\delta_{p_{a}}$ are much larger than the TAF in regimes $S W$ and $C S$, the $\delta_{p_{a}}$ are scaled down by specific factors (150 in regime $S W$, and 1500 in regime $C S)$ as labeled in Figure 3 so that the $\delta_{p_{a}}$ is comparable to the TAF in each regime.

Overall, transit service and system performance in regime $C S$ are closer to regime $S W$ than regime Prof. This reflects the functional forms and parameter values chosen for the example. By changing the calibration, the self-financing constraint could be tightened so that the operator in regime $C S$ would be forced to behave more like a profit-maximizer. Another observation is that the evolution of transit service and system performance in Figure 3 is consistent with the results for marginal capacity changes summarized in Table 2 for the model with $c_{b 2}=0$. The increase in fare and transit price in regime $S W$ indicates that capacity is large enough for the system to be operating on the upward-sloping portion of the U-curves noted in Table 2. As noted below, the downward-sloping portion of the U-curves are manifest when capacity is very low.

Under regime $C S$, with the base-case parameter values the operator responds to highway capacity expansion by reducing service frequency and raising the fare. The operator has to raise the fare because scale economies are lost as ridership declines. A different pattern can be generated by drastically reducing the fixed cost of transit from $k_{0}=50000$ to $k_{0}=1000$. With the quadratic cost parameter held fixed at $k_{2}=10$, transit now has scale diseconomies and the fare and transit user cost both decrease with highway capacity. (To economize on space, a figure displaying the results is omitted.) The original pattern of rising fares can be restored by increasing parameter $c_{b 2}$ in order to increase the degree of scale economies in user costs. This shows how the operator's behavior in regime $C S$ depends on the combined effect of scale economies in transit supply and user costs.

Insert Figure 3 here.

Figure 4 shows how auto price and trip volumes vary with highway capacity. In all regimes auto trips become cheaper, auto traffic rises, and transit ridership slowly decreases. Ridership in regime Prof remains at about half the level in the other regimes.

Insert Figure 4 here.

Changes in transit profit, consumers' surplus, and welfare are shown in Figure 5. Consumers' 
surplus and welfare increase with highway capacity in all regimes. Consistent with Prop. 3, transit profit decreases in regime Prof. By contrast, profit increases in regime $S W$ due to the combined effects of a lower frequency and a higher fare.

Insert Figure 5 here.

\subsection{The D-T paradox}

Zhang et al. (2014) have shown that with perfect substitutes and fixed total demand, the D-T paradox always occurs in regime $C S$. The paradox is no longer inevitable in the more general model here. Indeed, even the weak version of the paradox does not occur in the numerical examples just presented. Nevertheless, the analytical treatment in Section 3 suggests that the paradox is possible. According to Eq. (44), the weak paradox is more likely with: low auto volume, greater substitutability between auto trips and transit trips, severe transit crowding, long transit waiting times and high schedule delay costs, and strong scale economies in transit supply.

Extensive testing of the numerical example with different parameter value combinations reveals that the D-T paradox can occur, but only in extreme and unrealistic instances. One such case is identified in Table 5. Parameters $c_{a 0}$ and $c_{a 1}$ were raised in order to increase the cost of auto trips and reduce the auto modal share. Parameters $e_{1}$ and $e_{2}$ were increased greatly and brought close together $\left(e_{2} / e_{1}=0.985\right)$, so that auto trips and transit trips become close substitutes. Parameter $k_{2}$ of the transit cost function was set to 0 to assure positive transit scale economies at all levels of service frequency.

Insert Table 5 here.

Figure 6 displays the system behavior with the modified parameter values. Because of the high substitutability between auto and transit trips, auto and transit prices remain close together. Similar to the benchmark case, as highway capacity rises the operator reduces service frequency and raises the fare. Automobile usage and transit price both increase steadily. Up to a highway capacity of about $2100 \mathrm{veh} / \mathrm{h}$ the TAF remains slightly below the critical value $\delta_{p_{a}}$, and the price of auto trips therefore declines slightly. However, welfare declines monotonically so that the weak version of the D-T paradox occurs.

When highway capacity rises above $2100 \mathrm{veh} / \mathrm{h}$, the price of auto trips rises and welfare drops at an increasing rate. Both auto and transit users become worse off in this range so that the strong version of the D-T paradox appears as well. When highway capacity exceeds $5000 \mathrm{veh} / \mathrm{h}$, the transit operator cannot cover its costs with any combination of frequency and fare. Transit 
service ceases, and the auto is left as the only available mode.

The example diverges from the suggestive reasoning in Eq. (44) in one respect since the strong D-T paradox does not occur at very low auto volumes, but only once the auto share of trips reaches 29.5 percent.

Insert Figure 6 here.

Sensitivity analysis reveals that even the weak version of the D-T paradox occurs only when parameters $e_{1}$ and $e_{2}$ are both large, and the ratio $e_{2} / e_{1}$ is close to 1 , so that the two modes are close substitutes. With these values, the price elasticities of demand for both modes are implausibly high. This flies in the face of empirical evidence that auto and transit trips are both price inelastic, and suggests that neither version of the D-T paradox is likely to occur in practice.

\section{Conclusions}

The Downs-Thomson paradox is a classical example in transportation of the potentially adverse consequences of market failure. It occurs when expansion of a congested and untolled highway undermines the scale economies of a competing transit service, leaving users of both modes worse off. The standard analysis of the D-T paradox is narrow in scope, and incorporates several stringent assumptions. This paper extends the standard analysis in three ways. First, it generalizes the model to encompass elastic total travel demand, imperfect substitutability between automobile and transit trips, and transit crowding congestion. Second, it treats transit fare and service quality as separate decision variables for the transit operator. Third, it broadens consideration to alternative transit administration regimes. In the standard treatment it is assumed that the transit operator is obliged to meet a self-financing constraint and, in effect, responds passively to changes in ridership. Zhang et al. (2014) have recently considered profit maximization as a second regime. In this paper we study these two regimes and also a third one in which the operator maximizes welfare without a financing constraint.

To apply our more general model we formulate two versions of the D-T paradox. The weak version of the paradox occurs if highway capacity expansion reduces social surplus. The strong version occurs if the prices of both modes rise, and transit profits either fall or stay the same. The strong version can occur only if the weak version does as well.

The first part of the analysis entails treating the transit operator's response parametrically without explicitly considering its goals. Several general analytical results are obtained. First, highway expansion can lead to a fall in the price of transit only if the price of driving falls too (Proposition 1). Thus, drivers are more likely than transit riders to benefit from highway expansion. Second, improving transit service is not a necessary condition for transit users to be 
better off (Proposition 1), but it is necessary for transit ridership to increase or automobile traffic to fall (Proposition 2). Thus, in contrast to Mohring's (1972) analysis, transit ridership and service quality may not move in tandem.

The second part of the analysis considers the three alternative transit administration regimes explicitly. It confirms Zhang et al. (2014) that neither version of the D-T paradox can occur when the transit operator maximizes its profit, although highway capacity expansion reduces its profit (Proposition 3). It also establishes the intuitive result that capacity expansion cannot be harmful when the transit operator is an unconstrained welfare-maximizer (Proposition 4).

The most interesting results relate to the conventional transit administration regime in which the transit operator maximizes welfare subject to a zero-profit constraint. Highway capacity expansion does lead to deterioration in transit service (Proposition 5), but in contrast to Zhang et al. (2014) the D-T paradox is not inevitable. The weak version of the paradox can occur when the transit share of trips is high and transit service has substantial scale economies. However, despite extensive numerical analysis only rare instances of either version of the paradox were found that entailed implausibly high own-price and cross-price demand elasticities.

The key difference between the general model and the standard one appears to be imperfect substitutability. The intuition is clear: if auto and transit trips were not substitutable at all then demands for driving and taking transit would be independent. A change in travel conditions for one mode, such as highway capacity expansion, would have no effect on usage of the other mode. This is not the case in reality, but empirical studies generally find that cross-price elasticities of demand between transit and driving are low. Consequently, highway expansion does not induce many transit users to start driving, and the diverted flow is too small to offset the direct benefits of greater capacity in relieving traffic congestion. Furthermore, because ridership falls only slightly, the loss of transit scale economies is modest and transit users are not left much worse off.

In addition to searching for the D-T paradox, the numerical analysis offered some insightful comparisons of transit service in the three administration regimes. Among the three regimes, unconstrained social welfare-maximization provides the highest frequency at the lowest price, but it is likely to lose money. ${ }^{13}$ As highway capacity increases, both auto and transit prices decrease when the transit operator maximizes profit, but only the auto price decrease when the operator maximizes welfare. The results of the self-financing regime are intermediate between the other two.

\footnotetext{
${ }^{13}$ This result supports Basso and Jara-Díaz (2010) and Savage and Small (2010), who argue that social welfaremaximization is likely to require a subsidy to cover its costs.
} 
The analysis in this paper could be fruitfully extended in several directions of which we will mention just three. First, transit service normally exhibits scale economies, while highway traffic does not. Thus the chain reaction after transit expansion may not simply replicate that after highway expansion. ${ }^{14}$ Thus, it is also of interest to investigate the flip side of the paradox: an expansion of the transit service normally generates larger benefits than it would were the highway tolled or were the transit service not to exhibit economies of scale. ${ }^{15}$

Second, it has been implicitly assumed that the transit operator adjusts service immediately after the highway is expanded. In practice, such adjustments can take considerable time particularly major capacity investments. To perform an accurate cost-benefit analysis of a highway expansion, the accounting time horizon could be divided into two intervals: a short run in which transit service is fixed, and a long run in which it is endogenous. A distinction could also be made between the time required for fare adjustments and the (typically longer) time required to adjust frequency and other dimensions of capacity. Such an analysis would also be of interest in determining whether transit adjustments are beneficial or counterproductive.

Third, the analysis is limited to transit systems with a dedicated right of way. In the case of conventional bus service, transit vehicles share the road with cars. Travel time by bus depends on car traffic volume, and travel time by car depends on bus frequency (Ahn, 2009) and other characteristics of service such as bus size, number of loading bays and so on (Tirachini et al, 2014). To examine the prevalence of the D-T paradox it is necessary to account not only for interactions between car travel and transit on the demand side, but on the supply side as well. The analysis could be extended to include three modes - auto, bus, and Light Rail Transit (LRT). In a number of cities bus and LRT are close substitutes because LRT lines have been built on routes that are also served by bus. This suggests that expanding one public transit mode will undermine the scale economies of the other mode.

Acknowledgements. The authors would like to thank the anonymous referee for his constructive and helpful comments. This work was supported by grants from Hong Kong's Research Grants Council under project No. HKUST16205715, and a grant from the Social Sciences and Humanities Research Council of Canada.

\footnotetext{
${ }^{14}$ Szeto and Jiang (2014) have observed a Braess-like paradox in transit assignment that providing new lines to a transit network or increasing the frequency of an existing line may increase the total travel cost. Kilani et al. (2015) have recently identified the analytical conditions for the occurrence of such phenomenon.

${ }^{15} \mathrm{We}$ are grateful to an anonymous referee for making this observation.
} 


\section{Appendix.}

\section{A.1. Proof of Proposition 1.}

By assumption, $\frac{\partial c_{a}}{\partial v_{a}}, \frac{\partial c_{b}}{\partial v_{b}}>0, \frac{\partial c_{a}}{\partial s}, \frac{\partial c_{b}}{\partial f}<0, \frac{\partial v_{a}}{\partial p_{a}}, \frac{\partial v_{b}}{\partial p_{b}}<0$, and $\frac{\partial v_{a}}{\partial p_{b}}, \frac{\partial v_{b}}{\partial p_{a}}>0$. Therefore $1-\frac{\partial c_{a}}{\partial v_{a}} \frac{\partial v_{a}}{\partial p_{a}}>0$, $1-\frac{\partial c_{b}}{\partial v_{b}} \frac{\partial v_{b}}{\partial p_{b}}>0, \theta>0$, and $\delta_{p_{b}}-\delta_{p_{a}}=\theta \frac{\partial c_{a}}{\partial s} /\left(\frac{\partial c_{a}}{\partial v_{a}} \frac{\partial v_{a}}{\partial p_{b}}\left(1-\frac{\partial c_{a}}{\partial v_{a}} \frac{\partial v_{a}}{\partial p_{a}}\right)\right)<0$.

Part (i): From Eq. (10),

$$
\begin{aligned}
& \frac{d p_{a}}{d s}>0 \Leftrightarrow \frac{1}{\theta}\left[\left(1-\frac{\partial c_{b}}{\partial v_{b}} \frac{\partial v_{b}}{\partial p_{b}}\right) \frac{\partial c_{a}}{\partial s}+\frac{\partial c_{a}}{\partial v_{a}} \frac{\partial v_{a}}{\partial p_{b}} \delta\right]>0 \Leftrightarrow \delta>\delta_{p_{a}}, \\
& \text { hence } \frac{d p_{a}}{d s} \leq 0 \Leftrightarrow \delta \leq \delta_{p_{a}} .
\end{aligned}
$$

From Eq. (11),

$$
\begin{aligned}
& \frac{d p_{b}}{d s}>0 \Leftrightarrow \frac{1}{\theta}\left[\left(1-\frac{\partial c_{a}}{\partial v_{a}} \frac{\partial v_{a}}{\partial p_{a}}\right) \delta+\frac{\partial c_{a}}{\partial s} \frac{\partial c_{b}}{\partial v_{b}} \frac{\partial v_{b}}{\partial p_{a}}\right]>0 \Leftrightarrow \delta>\delta_{p_{b}}, \\
& \text { hence } \frac{d p_{b}}{d s} \leq 0 \Leftrightarrow \delta \leq \delta_{p_{b}} .
\end{aligned}
$$

Part (ii) follows from (i).

\section{A.2. Proof of Proposition 2.}

By assumption, $\frac{\partial c_{a}}{\partial v_{a}}, \frac{\partial c_{b}}{\partial v_{b}}>0, \frac{\partial c_{a}}{\partial s}, \frac{\partial c_{b}}{\partial f}<0, \frac{\partial v_{a}}{\partial p_{a}}, \frac{\partial v_{b}}{\partial p_{b}}<0$, and $\frac{\partial v_{a}}{\partial p_{b}}, \frac{\partial v_{b}}{\partial p_{a}}>0$.

Therefore $1-\frac{\partial c_{a}}{\partial v_{a}} \frac{\partial v_{a}}{\partial p_{a}}>0,1-\frac{\partial c_{b}}{\partial v_{b}} \frac{\partial v_{b}}{\partial p_{b}}>0, \theta>0, \delta_{v_{a}}, \delta_{v_{b}}<0$,

and $\delta_{v_{b}}-\delta_{v_{a}}=\frac{\partial c_{a}}{\partial s}\left(\frac{\partial v_{a}}{\partial p_{a}} \frac{\partial v_{b}}{\partial p_{b}}-\frac{\partial v_{a}}{\partial p_{b}} \frac{\partial v_{b}}{\partial p_{a}}\right) \theta /\left(\frac{\partial v_{a}}{\partial p_{b}}\left[\frac{\partial v_{b}}{\partial p_{b}}-\frac{\partial c_{a}}{\partial v_{a}}\left(\frac{\partial v_{a}}{\partial p_{a}} \frac{\partial v_{b}}{\partial p_{b}}-\frac{\partial v_{a}}{\partial p_{b}} \frac{\partial v_{b}}{\partial p_{a}}\right)\right]\right)>0$.

Part (i): According to Eqs. (12) and (13),

$$
\begin{aligned}
& \frac{d v_{a}}{d s}>0 \Leftrightarrow \frac{1}{\theta}\left[\frac{\partial v_{a}}{\partial p_{b}} \delta+\frac{\partial c_{a}}{\partial s}\left(\frac{\partial v_{a}}{\partial p_{a}}-\frac{\partial c_{b}}{\partial v_{b}}\left(\frac{\partial v_{a}}{\partial p_{a}} \frac{\partial v_{b}}{\partial p_{b}}-\frac{\partial v_{a}}{\partial p_{b}} \frac{\partial v_{b}}{\partial p_{a}}\right)\right)\right]>0 \Leftrightarrow \delta>\delta_{v_{a}}, \\
& \text { hence } \frac{d v_{a}}{d s} \leq 0 \Leftrightarrow \delta \leq \delta_{v_{a}}, \\
& \frac{d v_{b}}{d s}>0 \Leftrightarrow \frac{1}{\theta}\left[\left(\frac{\partial v_{b}}{\partial p_{b}}-\frac{\partial c_{a}}{\partial v_{a}}\left(\frac{\partial v_{a}}{\partial p_{a}} \frac{\partial v_{b}}{\partial p_{b}}-\frac{\partial v_{a}}{\partial p_{b}} \frac{\partial v_{b}}{\partial p_{a}}\right)\right) \delta+\frac{\partial c_{a}}{\partial s} \frac{\partial v_{b}}{\partial p_{a}}\right]>0 \Leftrightarrow \delta<\delta_{v_{b}}, \\
& \text { hence } \frac{d v_{b}}{d s} \leq 0 \Leftrightarrow \delta \geq \delta_{v_{b}} .
\end{aligned}
$$

Part (ii) follows from (i). 
A.3. Comparative static effects of changes in transit frequency $(f)$ and fare $\left(\tau_{b}\right)$

$$
\begin{aligned}
& \frac{d p_{a}}{d f}=\frac{1}{\theta} e_{2} \frac{\partial c_{a}}{\partial v_{a}} \frac{\partial c_{b}}{\partial f}<0, \\
& \frac{d p_{a}}{d \tau_{b}}=\frac{1}{\theta} e_{2} \frac{\partial c_{a}}{\partial v_{a}}>0, \\
& \frac{d p_{b}}{d f}=\frac{1}{\theta} \frac{\partial c_{b}}{\partial f}\left(1+e_{1} \frac{\partial c_{a}}{\partial v_{a}}\right)<0, \\
& \frac{d p_{b}}{d \tau_{b}}=\frac{1}{\theta}\left(1+e_{1} \frac{\partial c_{a}}{\partial v_{a}}\right)>0, \\
& \frac{d v_{a}}{d f}=-e_{1} \frac{d p_{a}}{d f}+e_{2} \frac{d p_{b}}{d f}=\frac{1}{\theta} e_{2} \frac{\partial c_{b}}{\partial f}<0, \\
& \frac{d v_{a}}{d \tau_{b}}=-e_{1} \frac{d p_{a}}{d \tau_{b}}+e_{2} \frac{d p_{b}}{d \tau_{b}}=\frac{1}{\theta} e_{2}>0, \\
& \frac{d v_{b}}{d f}=-e_{1} \frac{d p_{b}}{d f}+e_{2} \frac{d p_{a}}{d f}=-\frac{1}{\theta} \frac{\partial c_{b}}{\partial f}\left[e_{1}+\left(e_{1}^{2}-e_{2}^{2}\right) \frac{\partial c_{a}}{\partial v_{a}}\right]>0, \\
& \frac{d v_{b}}{d \tau_{b}}=-e_{1} \frac{d p_{b}}{d \tau_{b}}+e_{2} \frac{d p_{a}}{d \tau_{b}}=-\frac{1}{\theta}\left[e_{1}+\left(e_{1}^{2}-e_{2}^{2}\right) \frac{\partial c_{a}}{\partial v_{a}}\right]<0,
\end{aligned}
$$

where $\theta \equiv\left(1+e_{1} \frac{\partial c_{b}}{\partial v_{b}}\right)\left(1+e_{1} \frac{\partial c_{a}}{\partial v_{a}}\right)-e_{2}^{2} \frac{\partial c_{a}}{\partial v_{a}} \frac{\partial c_{b}}{\partial v_{b}}>0$.

\section{A.4. Comparative static effects of changes in highway capacity $(s)$}

When $\delta \equiv 0$, the equations governing changes in full prices and traffic volumes are:

$$
\begin{aligned}
& \frac{d v_{a}}{d s}=\frac{d v_{a}}{d p_{a}} \frac{d p_{a}}{d s}+\frac{d v_{a}}{d p_{b}} \frac{d p_{b}}{d s}, \\
& \frac{d v_{b}}{d s}=\frac{d v_{b}}{d p_{a}} \frac{d p_{a}}{d s}+\frac{d v_{b}}{d p_{b}} \frac{d p_{b}}{d s}, \\
& \frac{d p_{a}}{d s}=\frac{\partial c_{a}}{\partial v_{a}} \frac{d v_{a}}{d s}+\frac{\partial c_{a}}{\partial s}, \\
& \frac{d p_{b}}{d s}=\frac{\partial c_{b}}{\partial v_{b}} \frac{d v_{b}}{d s} .
\end{aligned}
$$

Solving the system of four equations using Cramer's Rule one obtains

$$
\begin{aligned}
& \frac{d v_{a}}{d s}=-\frac{1}{\theta} \gamma_{b} \frac{\partial c_{a}}{\partial s}, \\
& \frac{d v_{b}}{d s}=\frac{e_{2}}{\theta} \frac{\partial c_{a}}{\partial s},
\end{aligned}
$$




$$
\begin{aligned}
& \frac{d p_{a}}{d s}=\frac{1}{\theta}\left(1+e_{1} \frac{\partial c_{b}}{\partial v_{b}}\right) \frac{\partial c_{a}}{\partial s}, \\
& \frac{d p_{b}}{d s}=\frac{e_{2}}{\theta} \frac{\partial c_{b}}{\partial v_{b}} \frac{\partial c_{a}}{\partial s} .
\end{aligned}
$$

\section{A.5. Preferences underlying the linear demand functions (Section 4)}

The linear demand curves in Eqs. (22) and (23) can be generated from the following quadratic utility function: ${ }^{16}$

$$
U\left(v_{a}, v_{b}\right)=\alpha_{a} v_{a}+\alpha_{b} v_{b}-\frac{1}{2}\left(\beta_{a} v_{a}^{2}+2 \gamma v_{a} v_{b}+\beta_{b} v_{b}^{2}\right) .
$$

The representative consumer maximizes $U\left(v_{a}, v_{b}\right)-p_{a} v_{a}-p_{b} v_{b}$, resulting in the demand functions:

$$
\begin{aligned}
& v_{a}=\frac{\beta_{b} \alpha_{a}-\gamma \alpha_{b}}{\Delta}-\frac{\beta_{b}}{\Delta} p_{a}+\frac{\gamma}{\Delta} p_{b}, \\
& v_{b}=\frac{\beta_{a} \alpha_{b}-\gamma \alpha_{a}}{\Delta}-\frac{\beta_{a}}{\Delta} p_{b}+\frac{\gamma}{\Delta} p_{a},
\end{aligned}
$$

where $\Delta \equiv \beta_{a} \beta_{b}-\gamma^{2}>0$. In the model here it is assumed that $\beta_{a}=\beta_{b}$. Call the common value $\beta$. The demand functions in Eqs. (22) and (23) are recovered by translating parameters:

$$
e_{1}=\frac{\beta}{\beta^{2}-\gamma^{2}}, e_{2}=\frac{\gamma}{\beta^{2}-\gamma^{2}}, d_{0 a}=\frac{\beta \alpha_{a}-\gamma \alpha_{b}}{\beta^{2}-\gamma^{2}}, d_{0 b}=\frac{\beta \alpha_{b}-\gamma \alpha_{a}}{\beta^{2}-\gamma^{2}} .
$$

Parameters of the utility function can also be recovered from the demand functions:

$$
\beta=\frac{e_{1}}{e_{1}^{2}-e_{2}^{2}}, \gamma=\frac{e_{2}}{e_{1}^{2}-e_{2}^{2}}, \alpha_{a}=\frac{e_{1} d_{0 a}+e_{2} d_{0 b}}{e_{1}^{2}-e_{2}^{2}}, \alpha_{b}=\frac{e_{1} d_{0 b}+e_{2} d_{0 a}}{e_{1}^{2}-e_{2}^{2}} .
$$

\section{A.6. Optimal transit service in the linear model with no scale economies $\left(c_{b 2}=0\right.$ in Section} 5)

\section{Profit maximization}

$$
\begin{aligned}
& \tau_{b}^{\text {Prof }}=\frac{\left(1+e_{1} \sigma\right) g_{b}+e_{2} \sigma g_{a}}{2 \gamma_{a}}, \\
& f^{\text {Prof }}=\frac{\left(1+e_{1} \sigma\right) g_{b}+e_{2} \sigma g_{a}-2 \mu \gamma_{a} c_{b 1}}{2 \mu\left(1+e_{1} \sigma\right)}, \\
& v_{a}=\frac{1}{\left(1+e_{1} \sigma\right)}\left[g_{a}+e_{2}\left(\frac{\left(1+e_{1} \sigma\right) g_{b}+e_{2} \sigma g_{a}}{2 \gamma_{a}}+\mu c_{b 1}\right)\right],
\end{aligned}
$$

${ }^{16}$ See p.145 in Vives (1999); his notation has been modified to match that of the model here. 


$$
\begin{aligned}
& v_{b}=\frac{\left(1+e_{1} \sigma\right) g_{b}+e_{2} \sigma g_{a}-2 \mu \gamma_{a} c_{b 1}}{2\left(1+e_{1} \sigma\right)}, \\
& p_{a}=\tau_{a}+c_{a 0}+\frac{\sigma}{\left(1+e_{1} \sigma\right)}\left[g_{a}+e_{2}\left(\frac{\left(1+e_{1} \sigma\right) g_{b}+e_{2} \sigma g_{a}}{2 \gamma_{a}}+\mu c_{b 1}\right)\right], \\
& p_{b}=c_{b 0}+c_{b 1} \mu+\frac{g_{b}+\left(e_{1} g_{b}+e_{2} g_{a}\right) \sigma}{2 \gamma_{a}},
\end{aligned}
$$

where $\mu \equiv \sqrt{k / c_{b 1}}$.

\section{Welfare maximization}

$$
\begin{aligned}
& \tau_{b}^{S W}=\frac{\mu c_{b 1}\left[e_{1}+\sigma\left(2+e_{1} \sigma\right)\left(e_{1}^{2}-e_{2}^{2}\right)\right]-e_{2} \sigma g_{a}}{e_{1}\left(1+2 e_{1} \sigma+\left(e_{1}^{2}-e_{2}^{2}\right) \sigma^{2}\right)}, \\
& f^{S W}=\frac{1}{\mu}\left\{g_{b}+\frac{e_{2}\left(e_{1}+\gamma_{a}\right) \sigma g_{a}-2 \mu c_{b 1}\left(e_{1}^{2}+\left(e_{1}+\gamma_{a}\right) \sigma\left(e_{1}^{2}-e_{2}^{2}\right)\right)}{e_{1}\left(1+\left(e_{1}+\gamma_{a}\right) \sigma\right)}\right\}, \\
& v_{a}=\frac{\gamma_{a}\left(g_{a}+2 \mu c_{b 1} e_{2}\right)}{e_{1}\left(1+\left(e_{1}+\gamma_{a}\right) \sigma\right)}, \\
& v_{b}=g_{b}+\frac{e_{2}\left(e_{1}+\gamma_{a}\right) \sigma g_{a}-2 \mu c_{b 1}\left(e_{1}^{2}+\left(e_{1}+\gamma_{a}\right) \sigma\left(e_{1}^{2}-e_{2}^{2}\right)\right)}{e_{1}\left(1+\left(e_{1}+\gamma_{a}\right) \sigma\right)}, \\
& p_{a}=\tau_{a}+c_{a 0}+\sigma \frac{\gamma_{a}\left(g_{a}+2 \mu c_{b 1} e_{2}\right)}{e_{1}\left(1+\left(e_{1}+\gamma_{a}\right) \sigma\right)}, \\
& p_{b}=c_{b 0}+c_{b 1} \mu+\frac{\mu c_{b 1}\left[e_{1}+\sigma\left(2+e_{1} \sigma\right)\left(e_{1}^{2}-e_{2}^{2}\right)\right]-e_{2} \sigma g_{a}}{e_{1}\left(1+2 e_{1} \sigma+\left(e_{1}^{2}-e_{2}^{2}\right) \sigma^{2}\right)} .
\end{aligned}
$$

Consumers' surplus maximization subject to a self-financing constraint

$$
\begin{aligned}
& \tau_{b}^{C S}=\mu c_{b 1}, \\
& f^{C S}=\frac{\left(1+e_{1} \sigma\right) g_{b}+e_{2} \sigma g_{a}-2 \mu c_{b 1} \gamma_{a}}{\left(1+e_{1} \sigma\right) \mu}, \\
& v_{a}=\frac{\left(e_{1} g_{a}+e_{2} g_{b}\right) c_{b 1}\left(1+e_{1} \sigma\right) \mu+\left(g_{a}+e_{2} \mu c_{b 1}\right)\left[\left(1+e_{1} \sigma\right) g_{b}+e_{2} \sigma g_{a}-2 \mu c_{b 1} \gamma_{a}\right]}{\left(1+e_{1} \sigma\right)\left[\left(1+e_{1} \sigma\right) g_{a}+e_{2} \sigma g_{a}-\mu c_{b 1} \gamma_{a}\right]}, \\
& v_{b}=\frac{\left(1+e_{1} \sigma\right) g_{b}+e_{2} \sigma g_{a}-2 \mu c_{b 1} \gamma_{a}}{1+e_{1} \sigma}, \\
& p_{a}=\tau_{a}+c_{a 0}+\sigma v_{a}, \\
& p_{b}=c_{b 0}+c_{b 1} \mu+\mu c_{b 1} .
\end{aligned}
$$




\section{A.7. Parameter values for numerical example (Section 6)}

Values for parameters $e_{1}$ and $e_{2}$ are calibrated from the own- and cross-price demand elasticities reported by Litman (2004, 2012, 2015). Own-price elasticities with respect to full price fall in the range $[-0.6,-0.15]$, and cross-price elasticities in the range $[0.03,0.4]$. To be conservative, we assume $e_{2} / e_{1}=0.1$ and consider larger ratios in the sensitivity analysis. As in Zhang et al. (2014), the transit operating cost function is assumed to be increasing and convex with respect to service frequency. For automobile travel it is assumed that everyone drives alone so that person trips and vehicle trips are equivalent.

The value of parameter $c_{b 2}$ is important because it determines the degree of transit scale economies and the potential for the D-T paradox to occur. Parameter $c_{b 2}$ quantifies the combined costs of waiting time and schedule delay. Estimates of waiting time cost are usually expressed as a multiple of the unit cost of in-vehicle travel time, $\alpha$. For several decades the multiple was thought to be 2-3, but recent estimates are lower. In their meta-analysis of UK values of travel time, Abrantes and Wardman (2011) report a multiple of 1.70 (see Table 13 in their paper). A common assumption is that when transit service is frequent, users do not attempt to follow the timetable and wait on average for half the time headway between transit vehicle arrivals; i.e., $1 /(2 f) \cdot{ }^{17}$ The expected cost of waiting time then contributes an amount $1.70 \cdot(\alpha / 2)$ to parameter $c_{b 2}$.

The appropriate value for schedule delay costs depends on the distribution of users' preferred departure or arrival time. It is easy to show that if preferred times are uniformly distributed, and the time headway is uniform, the average cost of schedule delay is equal to $\beta \gamma /((\beta+\gamma)(2 f))$, where $\beta$ is the unit cost of arriving early and $\gamma$ is the unit cost of arriving late. If preferred times are more concentrated, or users cannot always board the first transit vehicle that arrives, the average cost of schedule delay will be higher. Similar to waiting time, estimates of $\beta$ and $\gamma$ are often expressed as multiples of $\alpha$. The estimates vary fairly widely. Wardman et al. (2012) report average values of $\beta=0.74 \alpha$ and $\gamma=1.72 \alpha$ (see Table 19, p.25, in their paper). This suggests that average schedule delay costs contribute to parameter $c_{b 2}$ an amount $0.5 \cdot(\alpha / 2)$ or rather higher. For waiting time and schedule delay costs together we adopt the value $c_{b 2}=2.5 \cdot(\alpha / 2)=1.25 \alpha$.

The 2014 median hourly wage in Hong Kong was reported to be $60 \mathrm{HK} \$$ (7.74US\$) by the Census and Statistics Department. Following Small and Verhoef (2007), the value of in-vehicle

${ }^{17}$ Ahn (2009) and Basso and Jara-Díaz (2012) also adopt this specification. 
travel time is assumed to be 50 percent of the wage. It follows that $\alpha=30 \mathrm{HK} \$ / \mathrm{hr}$ and $c_{b 2}=$ $37.5 \mathrm{HK} \$ / \mathrm{hr}$.

\section{References}

Abrantes, P.A.L., Wardman, M.R., 2011. Meta-analysis of UK values of travel time: An update. Transportation Research Part A: Policy and Practice 45(1), 1-17.

Adler., M, van Ommeren, J.N., 2015. Does public transit reduce car travel externalities? Tinbergen Institute Discussion Paper 15-011/VIII. Available at SSRN: http://ssrn.com/abstract=2553773 or http://dx.doi.org/10.2139/ssrn.2553773.

Ahn, K., 2009. Road pricing and bus service policies. Journal of Transport Economics and Policy 43(1), 25-53.

Anderson, M.L., 2014. Subways, strikes, and slowdowns: The impacts of public transit on traffic congestion. American Economic Review 104(9), 2763-2796.

Arnott, R., Small, K., 1994. The economics of traffic congestion. American Scientist 82(5), 446-455.

Arnott, R., Yan, A., 2000. The two-mode problem: Second-best pricing and capacity. Review of Urban and Development Studies 12, 170-199.

Basso, L.J., Jara-Díaz, S.R., 2010. The case for subsidisation of urban public transport and the Mohring effect. Journal of Transport Economics and Policy 44(3), 365-372.

Basso, L.J., Jara-Díaz, S.R., 2012. Integrating congestion pricing, transit subsidies and mode choice. Transportation Research Part A: Policy and Practice 46(6), 890-900.

Basso, L.J., Riquelme, I., Silva, H.E., 2015. Urban road capacity investments and the DownsThomson paradox. Paper presented at the International Transportation Economic Association Conference 2015, Oslo, June.

Beaudoin, J., Farzin, H., Lin, C.Y.C., 2015. Evaluating public transit investment in congested cities, June 24 (http://www.des.ucdavis.edu/faculty/Lin/transit_congestion_paper.pdf).

Bell, M.G.H., Wichiensin, M., 2012. Road use charging and inter-modal user equilibrium: The Downs-Thompson Paradox revisited. Energy, Transport, \& the Environment. Springer London, 373-383.

Bly, P.H, Johnston, R.H., Webster, F.V., 1987. A panacea for road congestion? Traffic Engineering and Control 28, 8-12; 19-20.

Cervero, R., 2003. Road expansion, urban growth, and induced travel: A path analysis. Journal of the American Planning Association 69(2), 145-163.

Dargay, J., Hanly, M., 1999. Bus fare elasticities. ESRC Transport Studies Unit, University College London, for UK Department of the Environment, Transport and the Regions (www.ucl.ac.uk).

Dechenaux, E., Mago, S.D., Razzolini, L., 2014. Traffic congestion: An experimental study of the Downs-Thomson Paradox. Experimental Economics 17(3), 461-487.

Denant-Boèmont, L., Hammiche, S., 2009. Public transit capacity and users' choice: An 
experiment on Downs-Thomson Paradox, 4th Kuhmo-Nectar Conference "transport and urban economics". Technical University of Denmark, Copenhagen.

de Palma, A., Kilani, M., Proost, S., 2015a. Discomfort in mass transit and its implication for scheduling and pricing. Transportation Research Part B: Methodological 71, 1-18.

de Palma, A., Lindsey, R., Monchambert, G., 2015b. The economics of crowding in public transport, working paper, July 24.

Downs, A., 1962. The law of peak-hour expressway congestion. Traffic Quarterly 16(3), 393409.

Duranton, G., Turner, M.A., 2011. The fundamental law of road congestion: Evidence from US cities. The American Economic Review 101(6), 2616-2652.

Goodwin, P.B., 1996. Empirical evidence on induced traffic. Transportation 23(1), 35-54.

Guo, P., Lindsey, R., Zhang, Z.G., 2014. On the Downs-Thomson paradox in a self-financing two-tier queuing system. Manufacturing \& Service Operations Management 16(2), 315322.

Hansen, M., Huang, Y., 1997. Road supply and traffic in California urban areas. Transportation Research Part A: Policy and Practice 31(3), 205-218.

Hensher, D.A., 1998. Establishing a fare elasticity regime for urban passenger transport. Journal of Transport Economics and Policy, 32(2). 221-246.

Holden, D.J., 1989. Wardrop's third principle: Urban traffic congestion and traffic policy. Journal of Transport Economics and Policy 23(3), 239-262.

Hotelling, H., 1929. The stability of competition. Economic Journal 39, 41-57.

Kilani, M., de Palma, A., and Proost, S., 2015. Do new transit lines necessarily improve user cost in the transit system? KU Leuven, Center for Economic Studies, Discussion Paper DPS15.15, July 9 (http://papers.ssrn.com/sol3/papers.cfm?abstract_id=2655567).

Kraus, M., 2012. Road pricing with optimal mass transit. Journal of Urban Economics 72(2-3), 81-86.

Litman, T., 2004. Transit price elasticities and cross-elasticities. Journal of Public Transportation 7(2), 37-58.

Litman, T., 2012. Understanding transport demands and elasticities: How prices and other factors affect travel behavior. September 10, Victoria Transport Policy Institute (http://www.vtpi.org/elasticities.pdf).

Litman, T., 2015. Transit price elasticities and cross-elasticities. May 28, Victoria Transport Policy Institute (http://www.vtpi.org/tranelas.pdf).

Mogridge, M.J.H., 1987. The Downs Thomson paradox and the transportation planning process. International Journal of Transport Economics 14(3), 283-311.

Mogridge, M.J.H., 1997. The self-defeating nature of urban road capacity policy: A review of theories, disputes and available evidence. Transport Policy 4(1), 5-23.

Mohring, H., 1972. Optimization and scale economies in urban bus transportation. American Economic Review 62(4), 591-604.

OECD, 2014. Valuing Convenience in Public Transport, Technical Report, ITF Round Tables 
(http://www.oecd.org/publications/valuing-convenience-in-public-transport9789282107683-en.htm).

Parry, I.W.H., Small, K.A.S, 2009. Should urban transit subsidies be reduced? American Economic Review 99(3), 700-724.

Savage, I., Small, K.A., 2010. A comment on 'Subsidisation of Urban Public Transport and the Mohring Effect'. Journal of Transport Economics and Policy 44(3), 373-380.

Sheffi, Y., 1985. Urban transportation networks. Prentice Hall, Englewood Cliffs, NJ

Small, K.A.S, Verhoef, E.T., 2007. The Economics of Urban Transportation, Routledge, London, UK.

Szeto, W.Y., Jiang, Y., 2014. Transit assignment: Approach-based formulation, extragradient method, and paradox. Transportation Research Part B: Methodological 62, 51-76.

Thomson, J.M., 1977. Great cities and their traffic. Victor Gollancz, London.

Tirachini, A., Hensher, D.A., Rose, J.M., 2014. Multimodal pricing and optimal design of urban public transport: The interplay between traffic congestion and bus crowding. Transportation Research Part B: Methodological 61, March, 33-54.

van den Berg, V.A., 2013. Serial private infrastructures. Transportation Research Part B: Methodological 56, 186-202.

Varian, H.R., 1992. Microeconomics Analysis. W. W. Norton \& Company Inc., New York.

Vives, X., 1999. Oligopoly Pricing. MIT Press, Cambridge, MA.

Wardman, M., Chintakayala, P., de Jong, G., Ferrer, D., 2012. European wide meta-analysis of values of travel time, Technical Report, Significance (http://www.significance.nl/papers/2012-European\%20wide\%20metaanalysis \%20of\%20values\%20of\%20travel\%20time.pdf).

Williams, H.C.W.L., 1998. Congestion, traffic growth and transport investment: The influence of interactions and multiplier effects in related travel markets. Journal of Transport Economics and Policy 32(2), 141-163.

Zhang, F., Yang, H., Liu, W., 2014. The Downs-Thomson Paradox with responsive transit service. Transportation Research Part A: Policy and Practice 70, 244-263. 


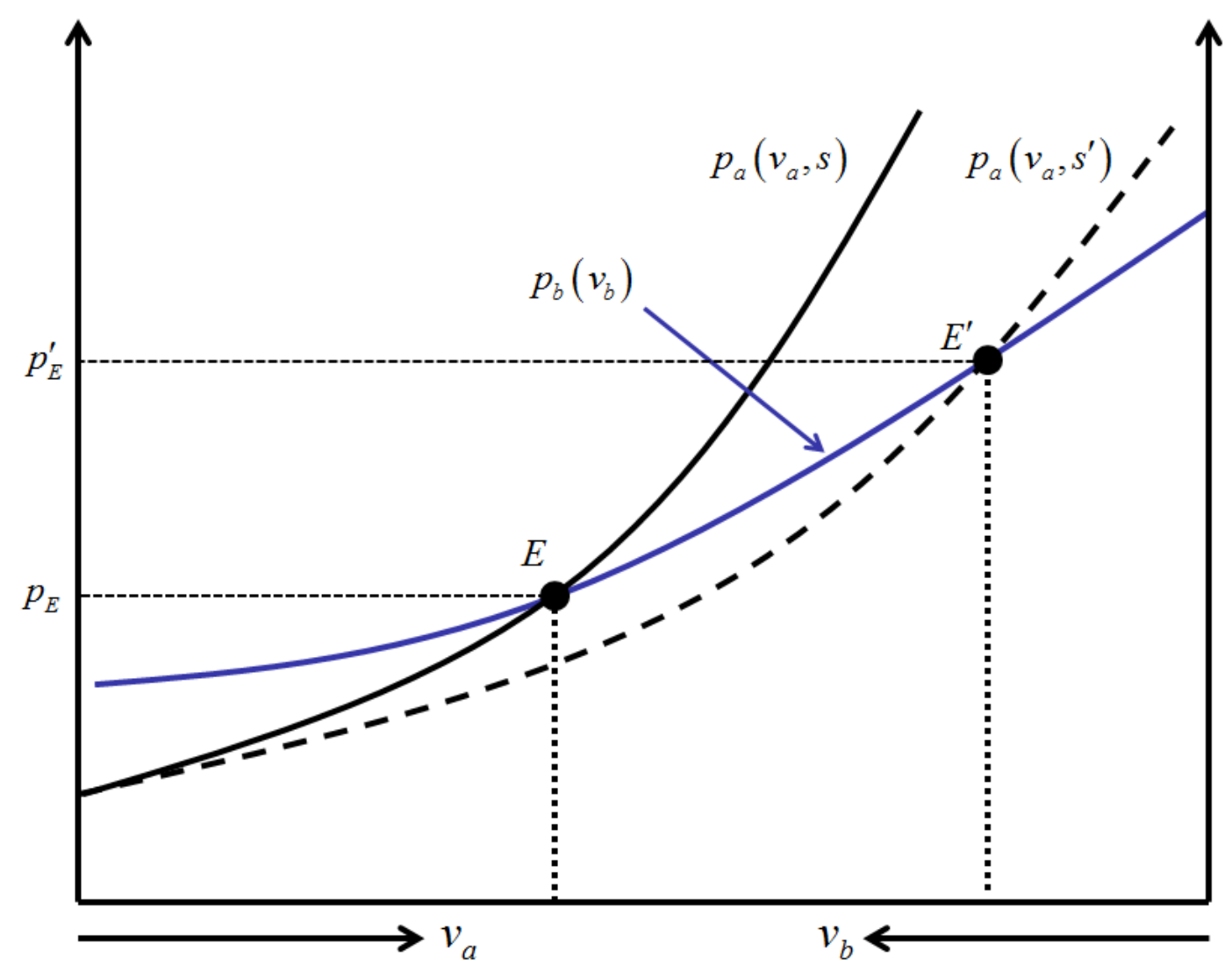

Figure 1. The D-T paradox in the standard model. 
Revised paper submitted to Transportation Research Part B on January 18, 2016

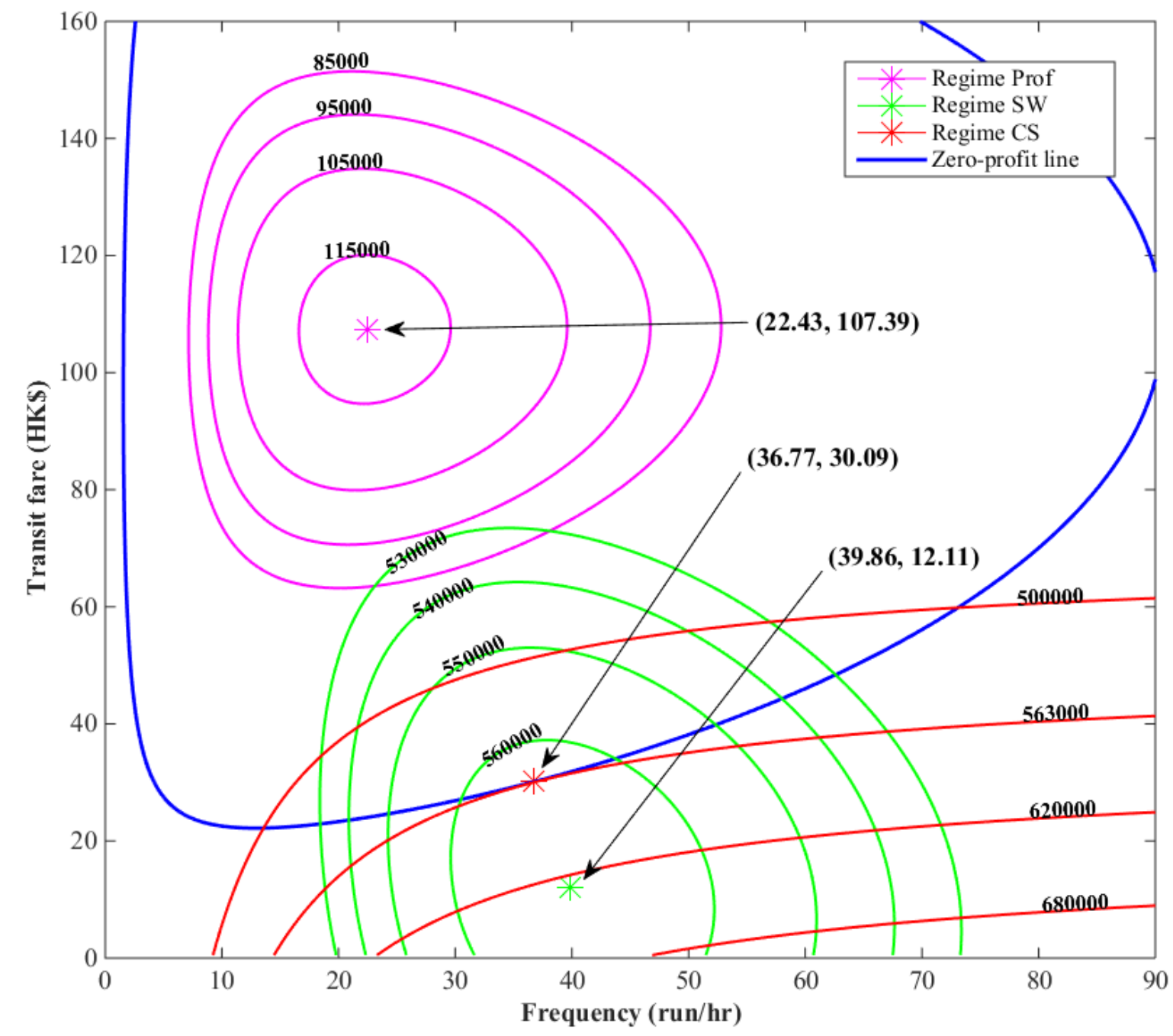

Figure 2. Optimal frequency and fare under different objectives (highway capacity: 2000veh/h). 

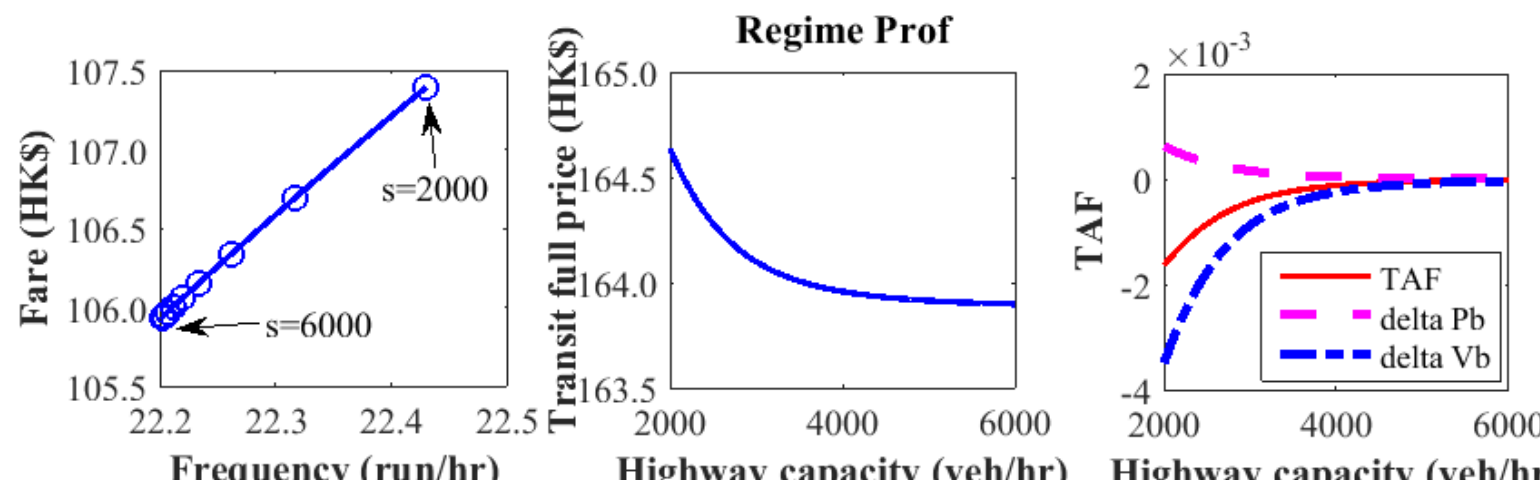

Frequency (run/hr)

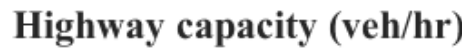

Highway capacity (veh/hr)
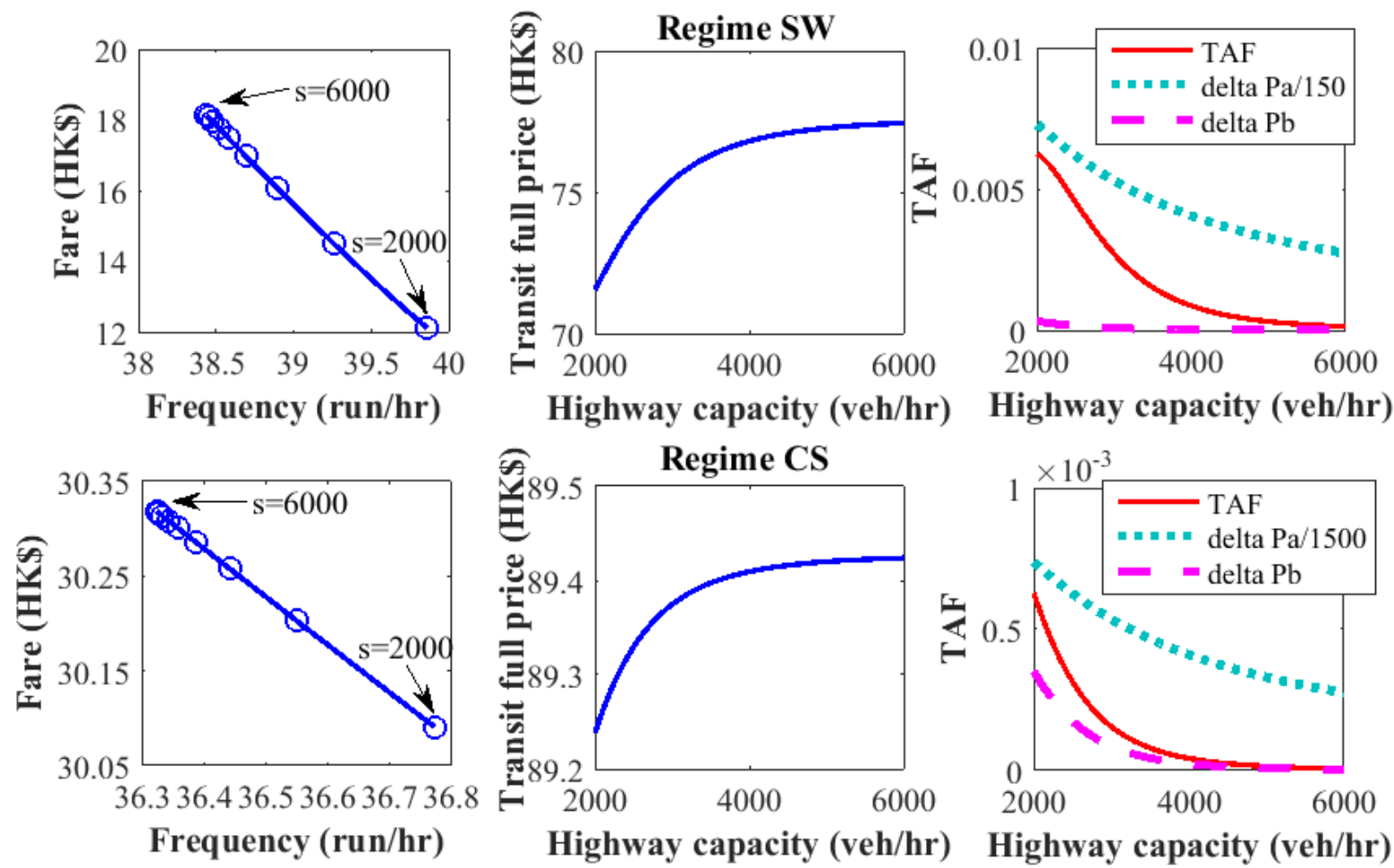

Figure 3. Transit service adjustment with the highway capacity expansion. 


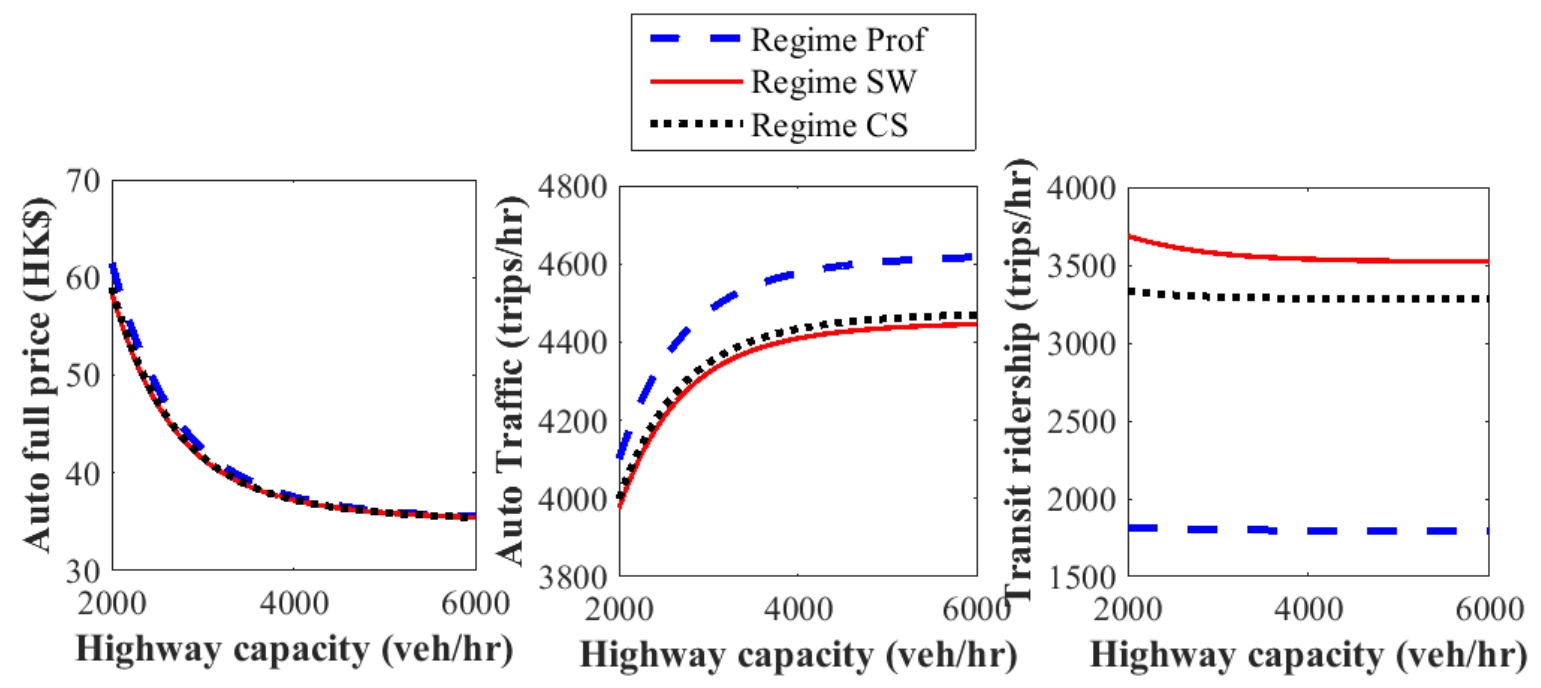

Figure 4. Changes in full prices and trips with highway expansion. 

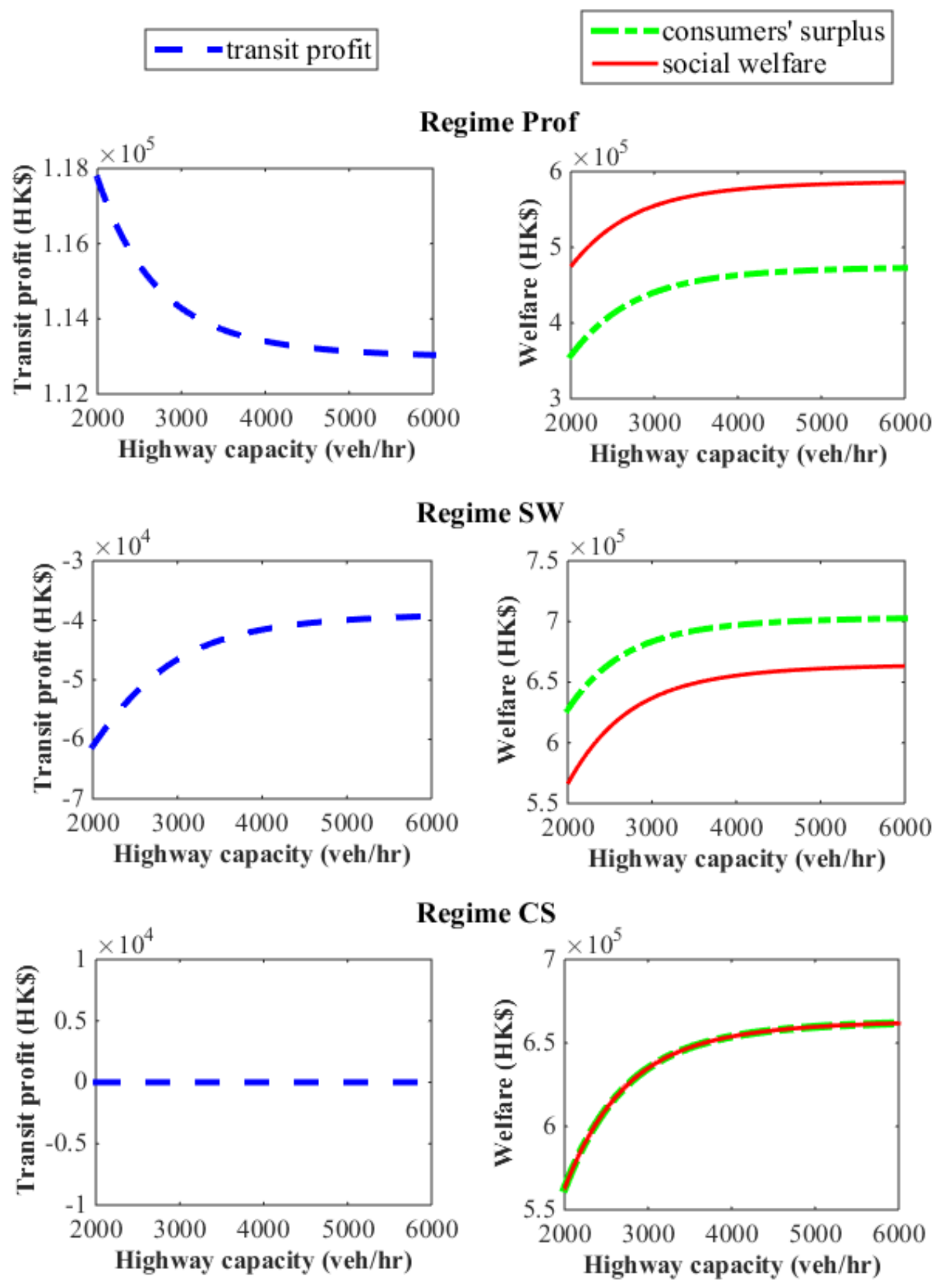

Figure 5. Changes in profit and welfare with highway expansion. 


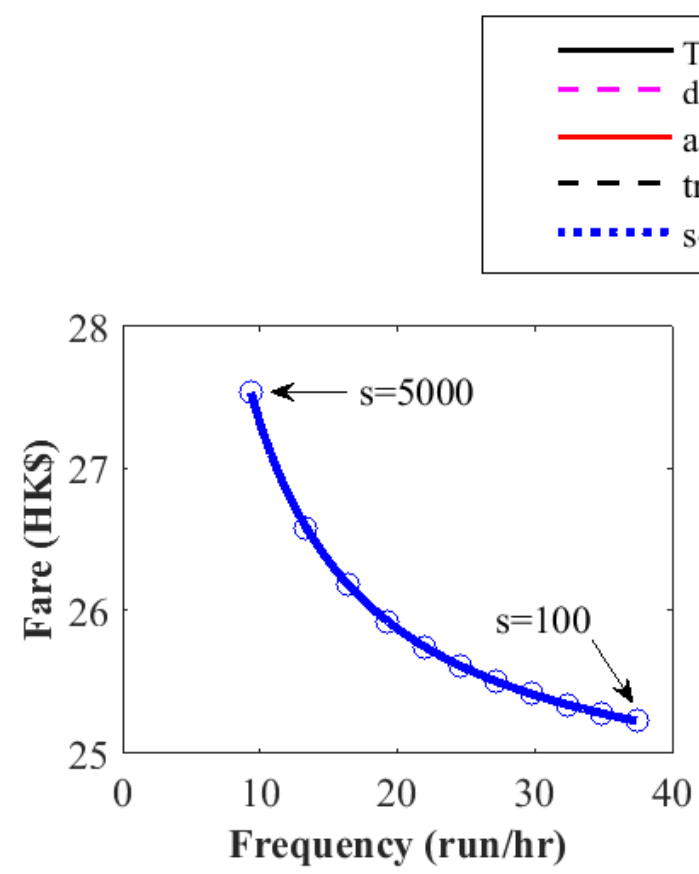

\section{TAF}

delta Pa

auto full price/volume

transit full price/volume

social welfare
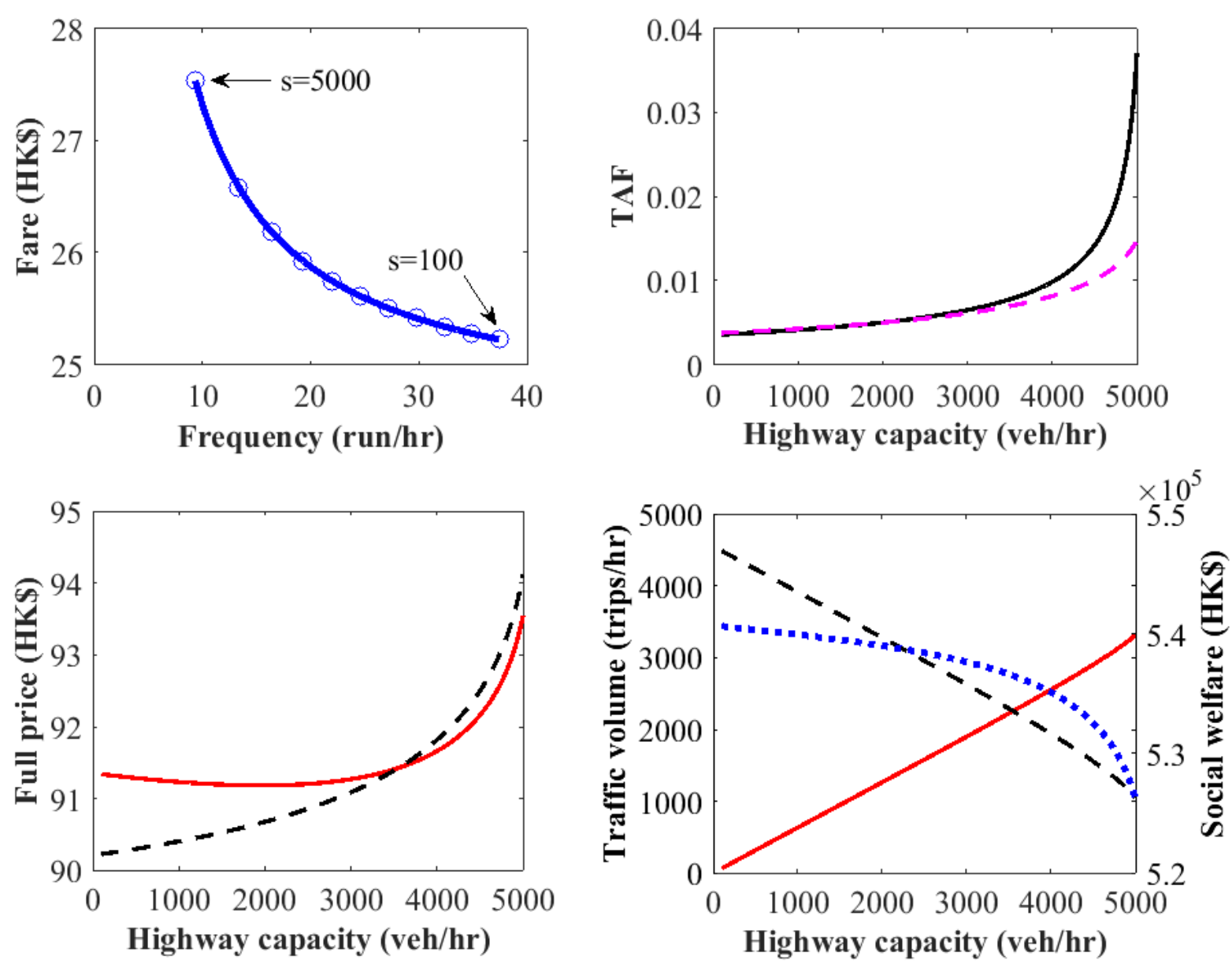

Highway capacity (veh/hr)

Figure 6. The D-T paradox in the self-financing regime $C S$. 
Table 1. Effects of highway expansion as a function of the Transit Adjustment Factor

\begin{tabular}{|c|c|c|c|c|c|c|}
\hline \multirow{2}{*}{ TAF $(\delta)$} & \multicolumn{3}{|c|}{ - } & \multicolumn{3}{|c|}{+} \\
\hline & $\left(-\infty, \delta_{v_{a}}\right)$ & $\left(\delta_{v_{a}}, \delta_{v_{b}}\right)$ & $\left(\delta_{v_{b}}, 0\right)$ & $\left(0, \delta_{p_{b}}\right)$ & $\left(\delta_{p_{b}}, \delta_{p_{a}}\right)$ & $\left(\delta_{p_{a}},+\infty\right)$ \\
\hline$p_{a}$ & $\downarrow$ & $\downarrow$ & $\downarrow$ & $\downarrow$ & $\downarrow$ & $\uparrow$ \\
\hline$p_{b}$ & $\downarrow$ & $\downarrow$ & $\downarrow$ & $\downarrow$ & $\uparrow$ & $\uparrow$ \\
\hline$v_{a}$ & $\downarrow$ & $\uparrow$ & $\uparrow$ & $\uparrow$ & $\uparrow$ & $\uparrow$ \\
\hline$v_{b}$ & $\uparrow$ & $\uparrow$ & $\downarrow$ & $\downarrow$ & $\downarrow$ & $\downarrow$ \\
\hline D-T paradox & 一 & - & - & - & - & Possible \\
\hline
\end{tabular}

Table 2. Effects of highway expansion with linear costs and $c_{b 2}=0$

\begin{tabular}{c|ccc}
\hline \hline & Regime Prof & Regime $S W$ & Regime $C S$ \\
\hline$\tau_{b}$ & $\downarrow$ & U-shaped & $-*$ \\
$f$ & $\downarrow$ & $\downarrow$ & $\downarrow$ \\
$p_{a}$ & $\downarrow$ & $\downarrow$ & $\downarrow$ \\
$p_{b}$ & $\downarrow$ & U-shaped & $-*$ \\
$v_{a}$ & $\uparrow$ & $\uparrow$ & $\uparrow$ \\
$v_{b}$ & $\downarrow$ & $\downarrow$ & $\downarrow$ \\
\hline \hline
\end{tabular}

$\overline{\text { Note: The comparative statics properties of the model for positive, but sufficiently small, values }}$ of $c_{b 2}$ are the same as in Table 2 except for the two cells marked with a *. 
Table 3. Functional forms and parameter values

\begin{tabular}{|c|c|c|}
\hline & Functional forms & Parameter values \\
\hline Auto travel time cost & $c_{a}\left(v_{a}, s\right)=c_{a 0}+c_{a 1}\left(\frac{v_{a}}{s}\right)^{\omega}$ & $\begin{array}{l}c_{a 0}=15 \mathrm{HK} \$ \\
c_{a 1}=1.5 \mathrm{HK} \$ \\
\omega=4\end{array}$ \\
\hline Transit travel time cost & $c_{b}\left(v_{b}, f\right)=c_{b 0}+c_{b 1}\left(\frac{v_{b}}{f}\right)+c_{b 2} \frac{1}{f}$ & $\begin{array}{l}c_{b 0}=40 \mathrm{HK} \$ \\
c_{b 1}=0.2 \mathrm{HK} \$ \cdot \mathrm{run} / \mathrm{trip}, \\
c_{b 2}=37.5 \mathrm{HK} \$ / \mathrm{h} .\end{array}$ \\
\hline Auto full price & $p_{a}=\tau_{a}+c_{a}$ & $\tau_{a}=20 \mathrm{HK} \$$ \\
\hline Transit full price & $p_{b}=\tau_{b}+c_{b}$ & \\
\hline Demand functions & $\begin{array}{l}v_{a}=d_{a 0}-e_{1} p_{a}+e_{2} p_{b}, \\
v_{b}=d_{b 0}-e_{1} p_{b}+e_{2} p_{a} .\end{array}$ & $\begin{array}{l}d_{a 0}=d_{b 0}=5000 \operatorname{trips} / \mathrm{h}, \\
e_{1}=20 \operatorname{trips} /(\mathrm{h} \cdot \mathrm{HK} \$), \\
e_{2}=2 \operatorname{trips} /(\mathrm{h} \cdot \mathrm{HK} \$) .\end{array}$ \\
\hline Transit operating cost & $K(f)=k_{0}+k_{1} f+k_{2} f^{2}$ & $\begin{array}{l}k_{0}=50,000 \mathrm{HK} \$ / \mathrm{h}, \\
k_{1}=1000 \mathrm{HK} \$ / \mathrm{run}, \\
k_{2}=10 \mathrm{HK} \$ \cdot \mathrm{h} / \mathrm{run}^{2}\end{array}$ \\
\hline
\end{tabular}


Table 4. Comparison of regimes with highway capacity $2000 \mathrm{veh} / \mathrm{h}$

\begin{tabular}{l|rrr}
\hline \hline & Regime Prof & Regime $S W$ & Regime CS \\
\hline Frequency $f($ run $/ \mathrm{h})$ & 22.43 & 39.86 & 36.77 \\
Fare $\tau_{b}(\mathrm{HK} \$)$ & 107.39 & 12.11 & 30.09 \\
Auto full price $p_{a}(\mathrm{HK} \$)$ & 61.50 & 58.41 & 58.98 \\
Transit full price $p_{b}(\mathrm{HK} \$)$ & 165.27 & 71.54 & 89.24 \\
Auto volume $v_{a}(\operatorname{trips} / \mathrm{h})$ & 4101 & 3975 & 3999 \\
Transit volume $v_{b}(\operatorname{trips} / \mathrm{h})$ & 1818 & 3686 & 3333 \\
Total traffic $v_{a}+v_{b}(\operatorname{trips} / \mathrm{h})$ & 5919 & 7661 & 7332 \\
Transit profit $\pi(\mathrm{HK} \$ / \mathrm{h})$ & $1.1773 \mathrm{e}+05$ & $-6.1113 \mathrm{e}+04$ & 0 \\
Consumers' surplus $C S(\mathrm{HK} \$ / \mathrm{h})$ & $3.5677 \mathrm{e}+05$ & $6.2719 \mathrm{e}+05$ & $5.6282 \mathrm{e}+05$ \\
Social welfare $S W(\mathrm{HK} \$ / \mathrm{h})$ & $4.7450 \mathrm{e}+05$ & $5.6608 \mathrm{e}+05$ & $5.6282 \mathrm{e}+05$ \\
\hline \hline
\end{tabular}

Table 5. Parameter value changes that yield the D-T paradox (units omitted)

\begin{tabular}{c|cccccc}
\hline \hline Parameters & $c_{a 0}$ & $c_{a 1}$ & $e_{1}$ & $e_{2}$ & $k_{1}$ & $k_{2}$ \\
\hline Benchmark & 15 & 1.5 & 20 & 2 & 1000 & 10 \\
D-T paradox & 60 & 70 & 2000 & 1970 & 3000 & 0 \\
\hline \hline
\end{tabular}

